\title{
Three decades of messenger RNA vaccine development
}

Rein Verbeke ${ }^{a, b}$, Ine Lentackera,b, Stefaan C. De Smedt ${ }^{a, b, 1 *}$ and Heleen Dewitte ${ }^{a, b, c, 1}$

${ }^{1}$ Last authors contributed equally to this work

aGhent Research Group on Nanomedicines, Faculty of Pharmacy, Ghent University, Ottergemsesteenweg 460, 9000 Ghent (Belgium)

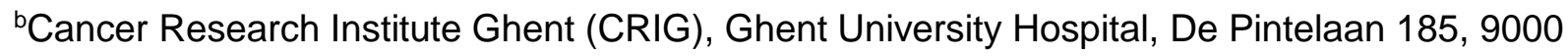

Ghent (Belgium)

'Laboratory of Molecular and Cellular Therapy, Department of Biomedical Sciences, Vrije Universiteit Brussel (VUB), Jette 1090, Belgium

*Corresponding author at: Ghent Research Group on Nanomedicines, Ottergemsesteenweg 460, 9000 Ghent, Belgium. Tel.: +32 926480 78; fax: +32 926481 89. E-mail address: Stefaan.DeSmedt@UGent.be (S.C. De Smedt). 


\begin{abstract}
In the early nineties, pioneering steps were taken in the use of mRNA as a therapeutic tool for vaccination. In the following decades, an improved understanding of the mRNA pharmacology, together with novel insights in immunology have positioned mRNA-based technologies as next-generation vaccines. This review outlines the history and current state-of-the-art in mRNA vaccination, while presenting an immunological view on mRNA vaccine development. As such, we highlight the challenges in vaccine design, testing and administration, key considerations in the design of mRNA-based vaccines and new opportunities that arise when packaging mRNA in nanoparticulate vaccines. Finally, we discuss the mRNA self-adjuvant effect as a critical, but dichotomous parameter that determines the safety, efficacy and strength of the evoked immune response.
\end{abstract}

\title{
Graphical abstract
}

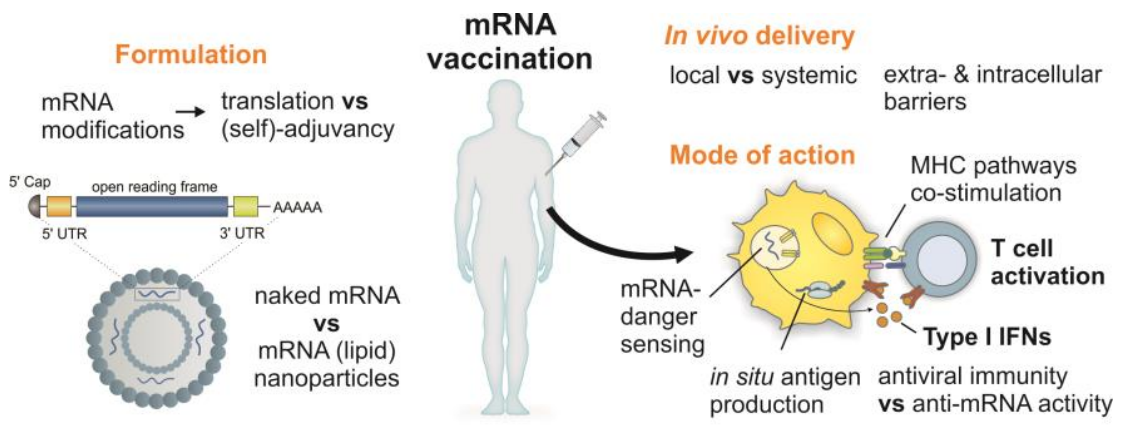

\section{Keywords:}

mRNA vaccine, lipid nanoparticle, cancer immunotherapy, type I IFN, checkpoint inhibition

\section{Highlights}

- $\quad$ mRNA represents an attractive source of antigen in vaccination approaches

- Both unformulated and nanoparticulate mRNA are used for direct in vivo vaccination

- Nanoformulation widens the administration and delivery options for mRNA vaccines

- The self-adjuvant effect of mRNA is a double-edged sword for vaccine efficacy

- Rationale for combining mRNA cancer vaccines with checkpoint inhibition 


\section{Table of Contents}

1. Introduction: the first steps in mRNA vaccine development 5

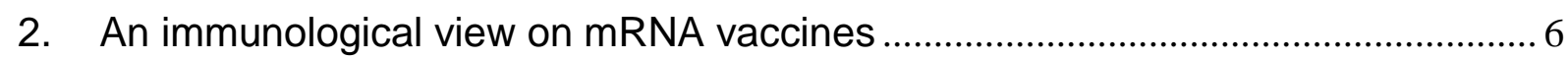

2.1. mRNA as an attractive source of antigen ............................................. 7

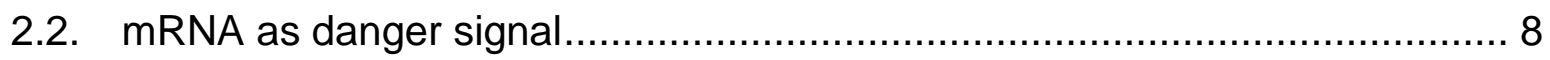

2.3. The paradigm for mRNA vaccine development ..................................... 10

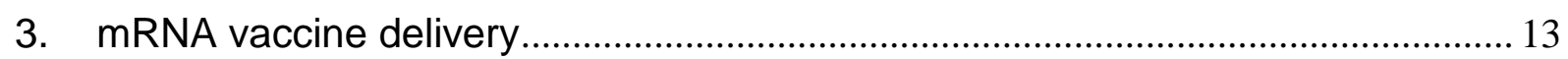

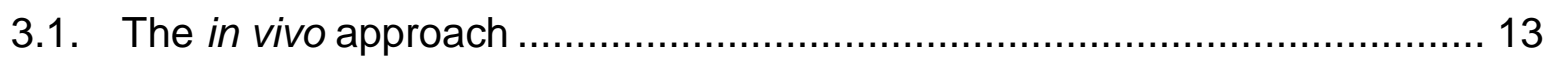

3.2. Naked, or unprotected mRNA vaccines for local delivery ........................ 14

3.3. Advanced delivery systems for mRNA ….......................................... 16

3.3.1. Nanoparticles: opening new avenues ......................................... 16

3.3.2. Designing and preparing lipid nanoparticles for mRNA delivery .......... 17

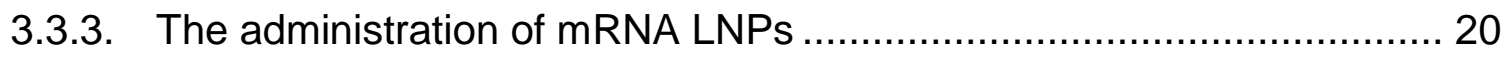

4. The "self-adjuvant" effects of mRNA: The Good, the Bad, and the Ugly..............2 24

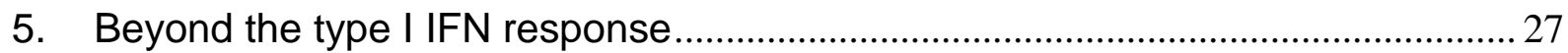

6. Combination of mRNA cancer vaccines with checkpoint therapies ........................30

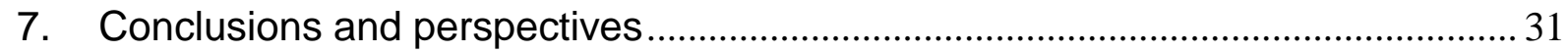

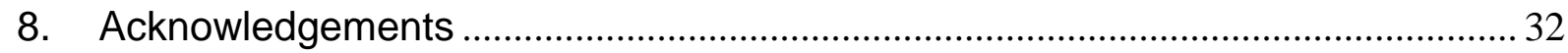

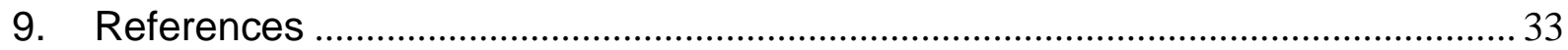




\section{Introduction: the first steps in mRNA vaccine development}

The concept of exploiting mRNA as a novel therapeutic drug class has taken off in 1989, when a start-up biotech company in San Diego, called Vical Incorporated, published their first successes. They demonstrated that mRNA packaged within a liposomal nanoparticle could successfully transfect mRNA into a variety of eukaryotic cells [1]. A few months later, Wolff et al. reported on their experiments where 'naked', unprotected mRNA was directly administrated in the muscle of mice. Although this actually served as a control for their liposome-mediated delivery, i.m. injection of unformulated mRNA resulted in expression of the encoded protein during a couple of days [2]. These preliminary data provided the first evidence that in vitro transcribed (IVT) mRNA could deliver the genetic information to produce proteins within living tissue. Importantly, this could be achieved without the need of a virus or non-viral vector, which countered the existing scepticism about the stability of mRNA in vivo. This encouraged the idea that mRNA might offer a valuable and safe alternative to plasmid DNA. Indeed, as the mRNA molecules only have to reach the cytosol in order to be translated at the ribosomes, they avert the risk of being integrated into the host genome.

Besides the therapeutic usage of mRNA to transiently replace faulty or missing proteins, it was suggested in the early 1990s that mRNA might be useful for the delivery of antigenic information to antigen-presenting cells (APCs) $[3,4]$. As pioneers, Martinon et al. showed that liposomes containing mRNA encoding the influenza virus nucleoprotein elicited virus-specific cytotoxic T lymphocytes (CTLs) [3]. In addition to this cellular immunity, Conry et al. demonstrated the activation of humoral immune responses, as they confirmed that a prophylactic vaccine consisting of mRNA encoding a carcinoembryonic antigen resulted in the induction of anti-tumoral antibody responses [4]. After three decades of research, mRNA vaccines have reached a new momentum, with many promising candidates entering the clinical trial stage. In this review, we will outline the most important fundamental insights that have led to our current understanding on how mRNA vaccines should be formulated and delivered. We will discuss on how the immunological outcome might vary from one mRNA vaccine platform to another, and where there might be room for further improvement to induce most effective but safe immune responses. 


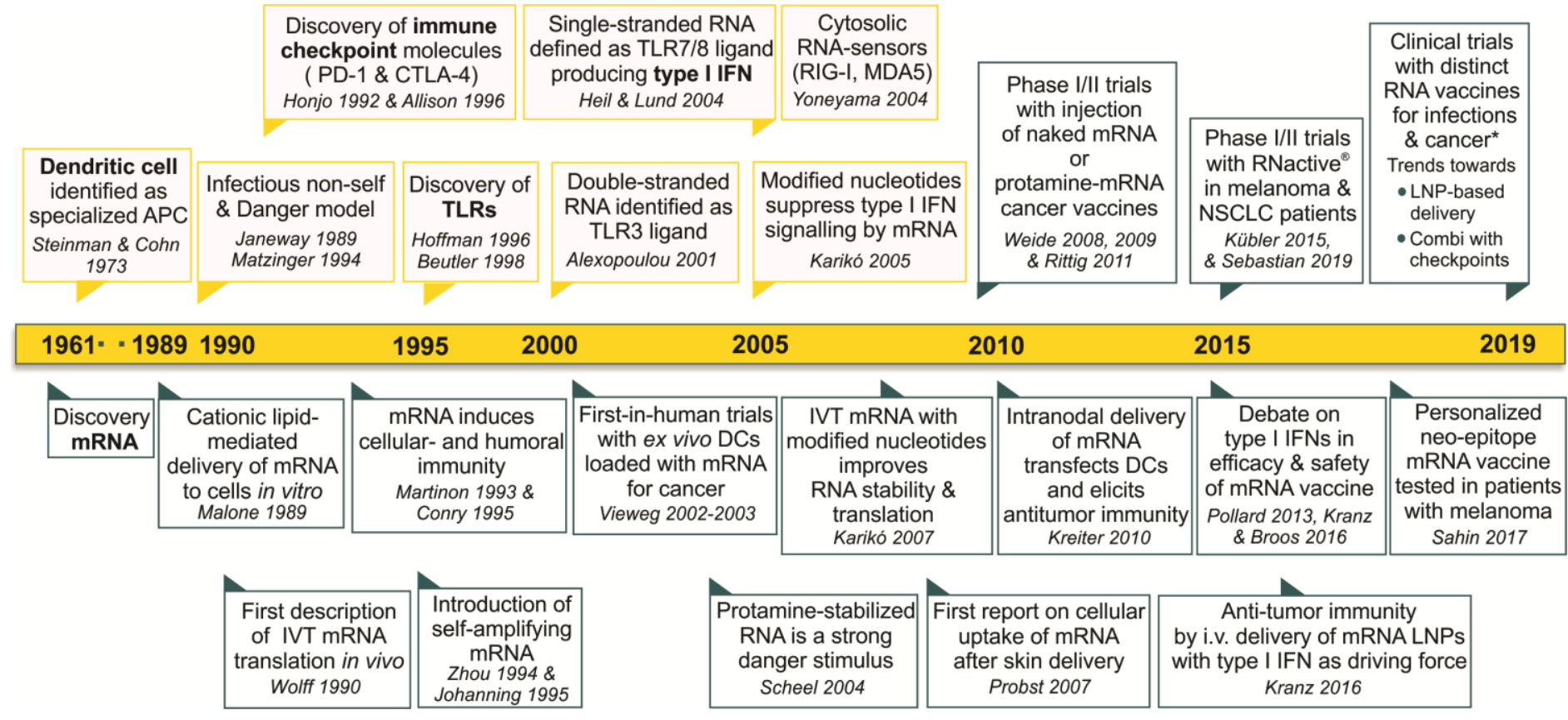

\section{Figure 1. Pioneering steps and milestones in the development of mRNA-based (cancer)}

vaccines. APC, antigen-presenting cell; PD-1, programmed cell death-1; TLR, Toll like receptor, RIG-I, retinoic acid -inducible gene I; IFN, interferon; NSCLC, non small cell lung carcinoma; LNP, lipid nanoparticle, IVT, in vitro transcribed; DC, dendritic cell; i.v., intravenous. ${ }^{*} \mathrm{~A}$ few dozen phase $\mathrm{I} / \mathrm{II}$ trials with mRNA vaccines are ongoing or recruiting patients, sponsored by leading biotech companies in the field.

\section{An immunological view on mRNA vaccines}

Shortly after the discovery of the dendritic cell (DC) in 1973 by Ralph Steinman and Zanvil Cohn, this cell type was identified as the accessory cell that is required to initiate $\mathrm{T}$ cell responses [5-7]. DCs are specialized in the uptake, processing and presentation of protein antigens to lymphocytes, which links innate and adaptive immune responses. Antigen signalling by DCs can either originate from the cytoplasm, which involves the presentation of antigenic peptides in major histocompatibility complex (MHC) class I molecules, or alternatively from the lysosomes that harbour fragments of endo- or phagocytized antigens which are loaded into MHC class II. These MHC complexes, thus loaded either with intracellular antigens in MHC-I or extracellular antigens in MHC-II, can then be recognized by the T cell receptor of $\mathrm{CD}^{+} \mathrm{T}$ cells or $\mathrm{CD} 4^{+} \mathrm{T}$ cells, respectively [8]. In addition to this antigen signalling, DCs fulfil their essential role in immunity by providing the necessary co-stimulation to trigger the activation of antigen-specific T cells. As a result, activated CD8 ${ }^{+}$CTLs can selectively eliminate cells that express this "foreign" antigen, such as infected host cells taken over by viruses, and tumor cells expressing "abnormal" proteins. CD4 ${ }^{+} \mathrm{T}$ helper cells, for their part, can provide the cognate help to further promote and support CTL activity. To achieve humoral immunity, B 
cells require the recognition of extracellular antigens by the $B$ cell receptor, as well as the interaction with activated T helper cells via the MHC class II pathway to enable the production of multifunctional, high-affinity antibodies. This knowledge on how DCs steer immune responses by specifically engaging different effector cells depending on the source and intracellular location of the antigen, has instigated the exploration of (cancer) vaccines, using different types of antigens.

\section{1. mRNA as an attractive source of antigen}

One of the key advantages of using antigen-encoding mRNA, is that it provides an easy way to evoke MHC-I presentation and elicit CTL responses. In similarity to viral infections, (IVT) mRNA allows the transient expression and accumulation of the selected antigens in the cytoplasm, which can then efficiently be processed into peptides and loaded in the MHC class I pathway, as illustrated in Figure 2. As such, the cytosolic presence of a few mRNA molecules can ensure extensive antigen presentation to CTLs, while proteins have to rely on less efficient cross-presentation pathways. Interestingly, also the MHC class II pathway can be targeted using mRNA as a source of antigen: this either after the secretion and recycling of the mRNA expressed proteins, or via direct shuttling of antigens from the cytosol to the lysosomes, e.g., promoted by the incorporation of a lysosomal targeting sequence in the mRNA construct [9, 10]. By comparison with protein-based vaccines, it was recently found that the extended antigen availability that can be obtained via mRNA had a profound effect on the magnitude and the affinity maturation of antibody responses, resulting in a more durable protection [1113].

Furthermore, mRNA has the advantage of offering a high degree of versatility in the type and number of antigenic determinants it encodes. For one, mRNA can code full-length proteins, thus avoiding restrictions concerning a patient's MHC haplotype. Alternatively, tandem constructs can be engineered which connect multiple antigenic epitopes within a single mRNA strand. Using this strategy, the company BioNTech AG has developed personalized mRNAbased cancer vaccines by identifying individual and immunogenic tumor mutations and producing on-demand mRNA vaccines encoding these neo-epitopes [14]. A first-in-human trial demonstrated the clinical feasibility and safety of this approach for advanced melanoma cancers: all vaccinated patients developed $\mathrm{CD}^{+}$and $\mathrm{CD}^{+} \mathrm{T}$ cell responses against the selected antigens, with some patients showing objective antitumor responses [15].

The fact that preparing a new mRNA construct tailored to a specific disease can be done in a straightforward and fast way, makes mRNA also an ideal candidate to trigger immunity against infectious diseases. These tend to rapidly mutate and therefore require a flexible and rapid production of appropriate vaccines that match the circulating viral strains. In this context, 
prophylactic mRNA vaccines were already considered safe and effective in phase I clinical trials for infectious diseases, such as influenza and rabies [16-18]. In small and large animal models, mRNA vaccines were able to elicit immunity against emerging infections such as zika, ebola and HIV [19-23]. Moreover, by the "in situ" expression of proteins within the cell, mRNA can achieve the production of properly folded and glycosylated antigens, offering solutions to the challenging production and limited stability of protein antigens. Moderna Therapeutics generated an mRNA vaccine encoding the five different subunits of the pentameric complex of the cytomegalovirus (CMV). Together with an mRNA sequence against the CMV glycoprotein $\mathrm{gB}$, this multiple-antigenic mRNA vaccine induced potent and durable neutralizing antibody titers in immunized mice and non-human primates [24].

\section{2. mRNA as danger signal}

Since the dawn of mRNA in vaccinology, the original model of immune recognition stating that $T$ cells and $B$ cells mount reactions against "non-self" proteins, while inducing tolerance against "self" proteins", which was based on a clonal selection theory, was found to be inadequate. In 1989, Charles Janeway proposed that antigen-presenting cells (APCs) should provide, in addition to a suitable antigenic determinant, a second co-stimulatory signal to activate lymphocytes. He stated that invading microbes are discriminated as non-self, not by the presence of foreign antigens, but through the existence of germline-encoded pattern recognition receptors (PRRs) that recognize infectious or microbial components, termed pathogen-associated molecular patterns (PAMPs) [25]. A few years later, Polly Matzinger elaborated on this concept and stated that APCs do not only respond to exogenous microbial signals, but are also activated by danger or alarm signals derived from damaged cells, such as heat shock proteins and extracellular nucleic acids [26]. The first real evidence to support this infectious non-self model and danger theory emerged in 1996, when Jules Hoffmann showed the involvement of Toll-like receptors (TLR) in how Drosophila reacts to pathogenic microorganisms. Interestingly, these TLRs had remarkable evolutionary conserved structural and functional similarities in mammals [27]. Two years later, the identification of TLR4 as the PRR that recognizes bacterial lipopolysaccharide (LPS) in mice by the group of Beutler, truly added flesh to the bones of this concept [28].Together with the pioneering work of Ralph Steinman in DC biology, these discoveries revolutionized our understanding of how immune responses are initiated and regulated.

While it has long been known that ('foreign') mRNA induces the production of type I interferon (IFN), in particular IFN- $\alpha$ and IFN- $\beta$, the exact mechanisms of mRNA's intrinsic immunogenicity remained unclear [29]. In the early 2000s, mRNA delivery was shown to trigger an antiviral activation state in DCs, which involves the recognition of single-stranded RNA through TLR7 and TLR8 located in the endosomes [30,31]. By the formation of secondary RNA structures 
or through the introduction of contaminants of double-stranded (ds) RNA fragments during the IVT mRNA production process, immune activation can be triggered via the endosomal TLR3 pathway. In addition to these TLRs, dsRNA was shown to activate the cytosolic RNA sensors retinoic acid inducible gene $\mathrm{I}(\mathrm{RIG}-\mathrm{I})$ and melanoma differentiation-associated protein 5 (MDA5) [32-34].

The binding of mRNA molecules to these danger sensors leads to downstream signalling via specific adaptor molecules (i.e. MyD88 for TLR7/8 and TRIF for TLR3), eventually resulting in the production of type I IFN and other pro-inflammatory cytokines (e.g., IL-6 and TNF- $\alpha$ ). In turn, type I IFNs bind autocrine or paracrine receptors, activating the Janus kinase-signal transducer activator of transcription (JAK-STAT) pathway, which regulates the gene expression of hundreds of proteins involved in antiviral immunity [35, 36]. Hence, these signalling pathways coordinate the activation and promotion of distinct innate and adaptive immune responses, referred to as the "self-adjuvant effect" of mRNA.

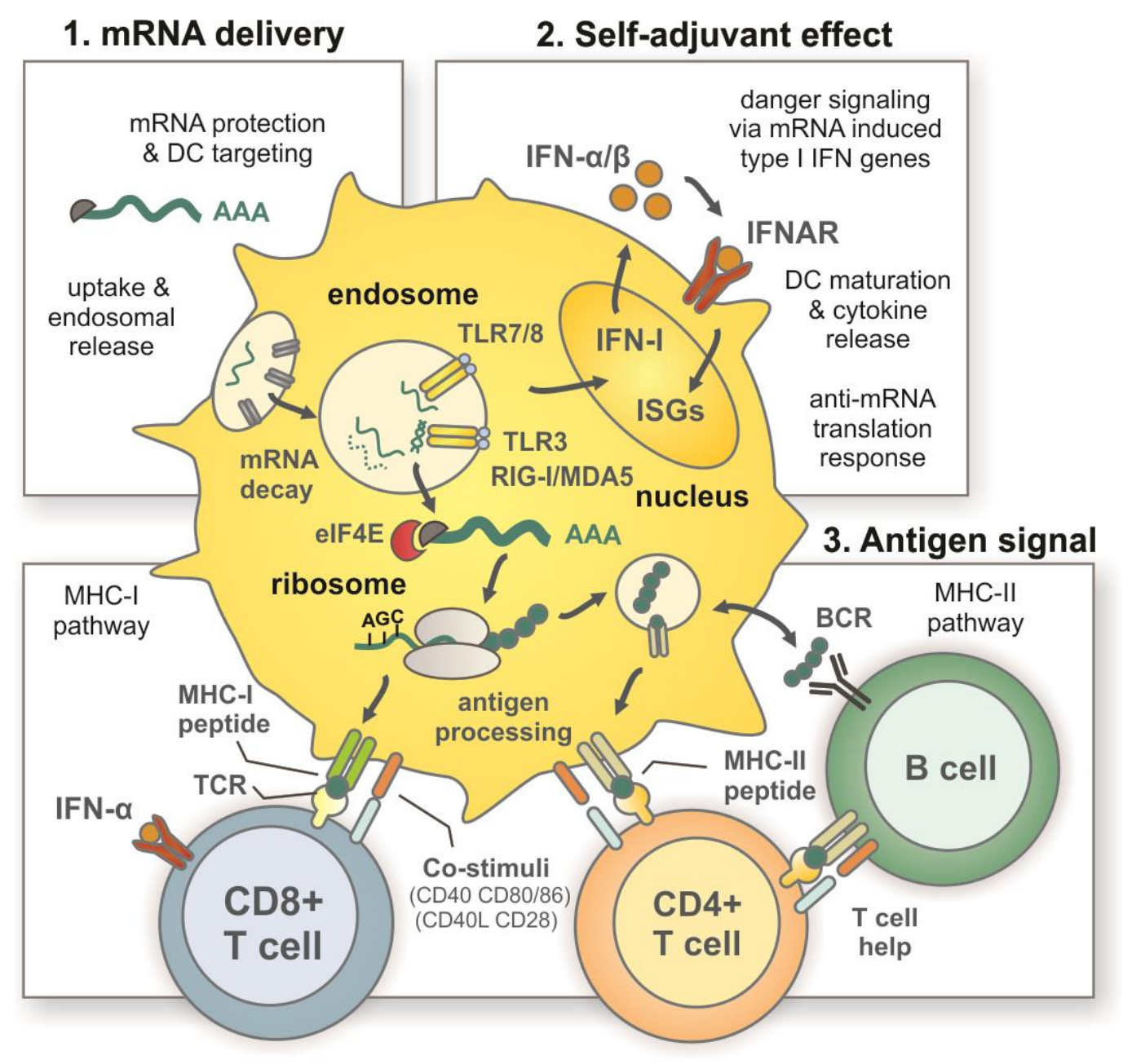

Figure 2. Mode of action of mRNA to induce adaptive immune responses. 1. Delivery: antigen-encoding mRNA should resist degradation by RNases and preferably reach APCs 
(DCs). mRNA molecules are taken up by receptor-mediated endocytosis and routed through the endo-lysosomal compartment. Only a fraction of mRNA escapes the endosomes, associates to elF4E proteins, and binds to the ribosomes, while the largest amount of mRNA molecules is degraded. 2. Adjuvant: mRNA is recognized by several PRRs, including endosomal TLRs and cytosolic RNA sensors, inducing signalling pathways that regulates the production of type I IFNs and other pro-inflammatory cytokines. Type I IFNs act as a doubleedged sword: it initiates the transcription of hundreds of interferon-stimulated genes (ISGs) involved in the DC maturation process and directly acts as a third cytokine signal for $\mathrm{T}$ cell activation, but also promotes antiviral enzymes that enhances mRNA degradation and inhibits the mRNA translation process. 3. Antigen presentation: the expression of antigenic proteins by the host translation machinery allows the antigen processing and presentation of antigenic peptides via the intracellular MHC-I pathway to CTLs, or allows the "in situ" production of secreted-antigen proteins that can be presented through the MHC-II pathway to helper T cells and $B$ cells.

\subsection{The paradigm for mRNA vaccine development}

A number of mRNA vaccine platforms have emerged over the years. The basic structure of IVT mRNA closely resembles "mature" eukaryotic mRNA, and consists of (i) a proteinencoding open reading frame (ORF), flanked by (ii) $5^{\prime}$ and $3^{\prime}$ untranslated regions (UTRs), and at the end sides (iii) a 7-methyl guanosine 5' cap structure and (iv) a 3' poly(A) tail (see Figure 3). The non-coding structural features play essential roles in the pharmacology of mRNA and can be individually optimized to modulate the mRNA stability, translation efficiency, and immunogenicity [35, 37, 38].

In 2004, Karikó and colleagues observed, while exposing ex vivo human DCs to mRNA from different sources, that these cells tolerated mammalian mRNA, while strong inflammatory cytokine responses were detected upon the delivery of mRNA derived from bacteria, necrotic mammalian cells and IVT mRNA [39, 40]. Interestingly, they found that the strongly reduced immune-modulatory capacity of endogenous mRNA could be attributed to the presence of modified nucleotides in the mRNA construct, such as methylated nucleosides or pseudouridine. As such, it was established that naturally occurring post-translational modifications to the mRNA nucleotides prevent the immune detection of endogenous mRNA, which allows the cells to discriminate it from pathological or invading mRNA. This presented new opportunities for mRNA development: by incorporating modified nucleosides, mRNA transcripts referred to as "nucleoside-modified $m R N A$ " could now be produced with reduced immunostimulatory activitiy, and therefore an improved safety profile. In addition, modified nucleosides allowed the design of mRNA vaccines with strongly enhanced stability and translation capacity, as they could avoid the direct antiviral pathways that are induced by type 
IFNs and are programmed to degrade and inhibit invading mRNA [41-45]. For instance, the replacement of uridine with pseudouridine in IVT mRNA was found to reduce the activity of 2'5'-oligoadenylate synthetase, which regulates the mRNA cleavage by RNase L. In addition, lower activities were measured for protein kinase $R$, an enzyme that is associated with the inhibition of the mRNA translation process. In a therapeutic setting, Kormann et al., demonstrated that nucleoside-modified mRNA encoding erythropoietin (Epo), in which $25 \%$ thio-uridine and 25\% 5-methylcytidine was incorporated, resulted in five times higher Epo levels compared to untreated mice, two weeks after i.m. administration. In contrast, no significant changes were detected with unmodified mRNA, which only evoked a substantial immune activation [44].

Besides the incorporation of modified nucleotides, other approaches have been validated to increase the translation capacity and stability of mRNA. One example is the development of "sequence-engineered mRNA". Here, mRNA expression can be strongly increased by sequence optimizations in the ORF and UTRs of mRNA, for instance by enriching the GC content, or by selecting the UTRs of natural long-lived mRNA molecules [46-50]. Another approach is the design of "self-amplifying $m R N A$ " constructs $[51,52]$. These are mostly derived from alphaviruses, and contain an ORF that is replaced by the antigen of interest together with an additional ORF encoding viral replicase. The latter drives the intracellular amplification of mRNA, and can therefore significantly increase the antigen expression capacity [53]. Already in 1995, Johanning et al. found that the i.m. injection of self-amplifying mRNA derived from the Sindbis virus, resulted in a ten-fold increase in protein expression levels, which could be maintained much longer (from 2 days up to 10 days) compared to nonamplifying mRNA [51].

Also, several modifications have been implemented at the end structures of mRNA. Antireverse cap (ARCA) modifications can ensure the correct cap orientation at the $5^{\prime}$ end, which yields almost complete fractions of mRNA that can efficiently bind the ribosomes [54]. Other cap modifications, such as phosphorothioate cap analogs, can further improve the affinity towards the eukaryotic translation initiation factor $4 \mathrm{E}$ (elF4E), and increase the resistance against the RNA decapping complex $[55,56]$. Correlations were found between the elongation of the poly $(A)$ tail of mRNA and the duration of expression, and specific modifications at the 3' UTR were reported that can slow-down the decay of the poly $(A)$ tail by deadenylation $[57,58]$. Also, more exotic approaches have been suggested, such as the generation of circularengineered RNAs that render resistance towards exonuclease-mediated degradation $[59,60]$. Recently, it was demonstrated that the delivery of synthetic polyamine complexes preassembled with mRNA and elF4E proteins resulted in significantly higher expression 
efficiencies compared to mRNA alone, which could be attributed to a higher stability and recruitment of these complexes to the ribosomes [61].

Conversely, by modifying its structure, the potency of mRNA to trigger innate immune responses can be further improved, but to the detriment of translation capacity. The company CureVac AG found that by stabilizing the mRNA with either a phosphorothioate backbone, or by its precipitation with the cationic protein protamine, antigen expression was diminished, but stronger immune-stimulating capacities could be obtained [62, 63]. This instigated the development of protamine-complexed mRNA molecules to function either solely as an immune adjuvant for peptide and protein-based vaccines (i.e. RNAdjuvant ${ }^{\circledR}$ ), or in a two-component mRNA platform consisting of antigen-encoding mRNA combined with protamine-mRNA complexed molecules in order to increase the vaccine's immunogenicity (i.e. RNAactive ${ }^{\circledR}$ ) [64, 65].

Taken together, these findings resulted in a paradigm of the design of mRNA formulations for vaccination. One strategy is to use mRNA which is fully optimized to obtain a strong adjuvant effect, another is to work with 'modified' mRNA with high translation capacity, and thus improved antigen bio-availability $[43,62]$. With respect to vaccination purposes, one should consider that the modifications that favour the mRNA's translation capacity involve a partial or complete reduction of the interaction between mRNA molecules and one or multiple virusspecific PRRs [66]. As such, this might come at the cost of the adjuvant effect of the mRNA vaccine. After all, both outcomes are oppositely regulated by type I IFN-induced genes. The priority is often given to the translation capacity of mRNA with the idea to improve the antigen availability. Yet, from an immunological point-of-view, the innate immune sensing of mRNA, which evokes the phenotypic immune profiling and cytokine milieus, is at least equally important. Indeed, these innate immune signals will trigger and guide the choice of effector responses, which is of essential importance for the vaccine's therapeutic value [67]. Notwithstanding, the potency of this self-adjuvant effect of mRNA must be weighed against the risk of any adverse reaction inherent to it, including inflammation reactions and auto-immune events [68]. This key challenge of finding an optimal balance between the translation capacity and adjuvanticity of mRNA vaccines, in order to obtain adequate, but safe immunogenicity, will be discussed later on in this review (see section 4). 


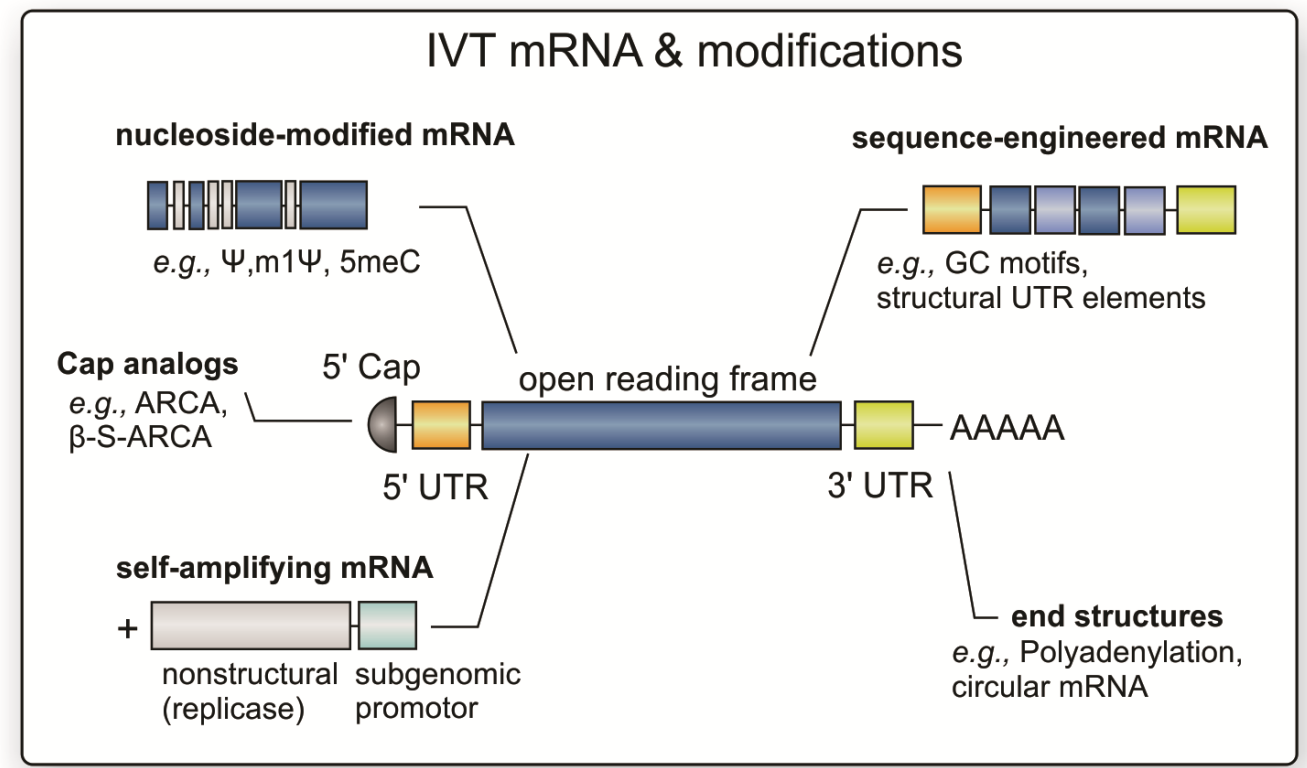

Figure 3. Structural features of IVT mRNA. Figure shows the structural elements of IVT mRNA. Each of these elements can be optimized and modified in order to modulate the stability, translation capacity, and immune-stimulatory profile of mRNA.

\section{3. mRNA vaccine delivery}

\subsection{The in vivo approach}

The first human trials evaluating mRNA delivery were focused on an ex vivo approach, where monocyte-derived DCs were transfected with antigen-encoding mRNA and re-infused into the patients as a cellular vaccine [69]. Excellent reviews on such mRNA-based DC vaccines can be found elsewhere $[70,71]$. Over the years, the focus has started to shift towards the direct administration of mRNA. In general, the alternative of in vivo approaches that directly target mRNA to APCs, holds a number of key benefits to ex vivo generated DC vaccines. First of all, the costly and laborious ex vivo steps associated with the isolation and culturing of patientspecific DCs are avoided. Secondly, the in vivo delivery of mRNA more closely mimics a natural (viral) infection, which may benefit the vaccine's efficacy; multiple immune cells and non-immune cells can be directly transfected in their natural habitat, which allows the immediate innate immune activation and coordinated signalling to adaptive immune cells. Moreover, crucial immune events, such as the release of inflammatory cytokines and chemokines, that peak within a couple of hours after transfection, can be lost in time and place when preparing ex vivo $\mathrm{DC}$ vaccines $[72,73]$.

Despite the numerous advantages of mRNA vaccines to target APCs in situ, there are also a number of challenging technical hurdles that need to be overcome for mRNA to be successfully delivered to their target cells. Independent of the administration route, several evolutionary 
barriers are designed to prevent any intrusion of foreign nucleic acids and thus limit the delivery of exogenous mRNA [74]. In the early events after administration, mRNA should resist the degradation by RNAses present in the tissues and bloodstream. Since mRNAs are large and polyanionic molecules, they cannot passively diffuse across the cell membrane. Therefore, mRNA molecules rely on active transportation via endocytic uptake mechanisms. This implies that even when intact mRNA is taken up by APCs, almost all mRNA molecules will eventually be entrapped and degraded in the endo-lysosomal compartment. Moreover, anti-viral host defence mechanisms are induced by the mRNA immune recognition increasing enzymatic activities that destroy mRNA and inhibit its further cellular translation (see section 2.2) [45].

\subsection{Naked, or unprotected mRNA vaccines for local delivery}

Despite these well-documented delivery hurdles, 'naked', unprotected mRNA has been evaluated to trigger protein expression after injection via different administration routes. The earliest studies have explored the i.m., subcutaneous (s.c.), and intradermal (i.d.) routes, showing detectable protein expression levels at the injection site, which also resulted in adaptive immune responses $[4,51,75]$. Little by little, more came to be known on the mode of action of these 'naked' mRNA vaccines, and the cell subsets involved in the response. In 2007, Probst et al. proved that somatic cells of the dermis, such as muscle cells, fibroblasts or keratinocytes, are capable of taking up $\beta$-galactosidase-coding mRNA in a saturable and iondependent manner [76]. More details on mRNA uptake were uncovered by Lorenz et al., who used a fibroblast cell line to demonstrate that mRNA molecules are initially recognized by scavenger receptors prior to their internalization by caveolae and lipid raft-dependent uptake mechanisms [77]. With respect to their intracellular fate, they showed that mRNA molecules are routed through the endocytic pathways, with the largest fraction ending up in the lysosomes, while only a limited fraction of mRNA molecules is being released to the cytosol. Only years later, the involvement of immune cells in the uptake of unformulated mRNA was identified: skin-resident DCs were capable of engulfing naked mRNA via macropinocytosis and could trigger T cell immunity in mice [78]. The involvement of different cell types in the uptake of mRNA vaccines was confirmed for the RNActive ${ }^{\circledR}$ vaccine technology. Upon i.d. application, both vaccine components, sequence-engineered mRNA and protamine-complexed mRNA, were taken up by both immune cells and non-immune cells, with the highest frequencies detected within macrophages, DCs and neutrophils [79]. This coincided with an increased expression of activation markers by resident APCs, as well as a transient production of distinct cytokines and chemokines, demonstrating the self-adjuvanticity of this formulation. In addition to these rather locally induced effects, two independent studies respectively testing RNActive ${ }^{\circledR}$ or a formulation of sequence-engineered mRNA alone, suggested the migration of activated 
immune cells toward the lymph nodes (LNs), as they could also detect innate immune signals and mRNA-encoded antigens in the draining LNs $[79,80]$

Over the years, it became clear that the chosen injection route plays a major role regarding the cell types that come in contact with the mRNA and the potency of the evoked immune response. As such, direct delivery of the mRNA into the LNs (i.n. injections) rapidly became a favourable delivery route to ensure delivery to APCs. This was underscored by Kreiter and colleagues, who reported that the potency of an unmodified, naked mRNA vaccine to induce $T$ cell immunity could be drastically increased by injecting it i.n. compared to injections in the skin [81]. They demonstrated that within the LNs, naked mRNA was predominantly taken up by resident DCs (and macrophages) via macropinocytosis [82]. Furthermore, the increasing knowledge on the extensive infiltration of immune cells into various tumor types, also prompted the investigation of intratumoral (i.t.) application of naked mRNA. Indeed, tumor-infiltrating $\mathrm{CD} \mathrm{a}^{+}$cross-presenting DCs were mainly responsible for mRNA uptake after injection in different subcutaneous murine tumor models, resulting in mRNA expression for $>5$ days [83, 84].

Of note: this story may drastically change when evaluating self-amplifying mRNA. First of all, it was found that APCs could not be directly transfected with self-amplifying mRNA, which is significantly longer in length (10kb versus $2-3 \mathrm{~kb}$ for nonamplifying mRNA). Nevertheless, this inability to directly transfect APCs, did not abrogate the priming of CTLs following the i.m. delivery of a self-amplifying mRNA vaccine [85]. To elucidate the underlying mechanisms, Lazzaro et al. investigated the respective contribution of (transfected) muscle cells and (nontransfected) professional APCs to the CTL priming. They concluded that APCs could take up antigens that were produced by the transfected muscle cells, and that cross-presentation of the myocyte-expressed antigens was the mechanism leading to the induction of CTL responses [85]. As such, the transfection of somatic cells, such as myocytes, may contribute to the magnitude and duration of antigen availability, while the activation of TLR and cytosolic RNA sensors in these cells can lead to local inflammation and infiltration of cross-presenting DCs.

In attempts to further promote innate immune activation, combinations of antigen-encoding (unmodified) mRNA and immune-attractants or immunostimulants were tested, which were implemented in the vaccine as protein or as mRNA transcripts. Intradermal injections of granulocyte-macrophage colony-stimulating factor (GM-CSF) contributed to the infiltration of monocytes, and to the migration of mRNA-transfected, matured DCs to the LNs [86, 87]. The co-delivery of immune adjuvants, such as polyinosinic:polycytidylic acid (Poly(l:C)) and lipopolysaccharide (LPS), was found to rapidly mature the APCs, which abrogated the cellular uptake of mRNA molecules [82]. As such, these adjuvants caused a detrimental reduction of 
the mRNA transfection capacity, thus antigen bio-availability for $\mathrm{T}$ cell priming. Alternatively, Van Lint et al. showed increased T cell stimulatory effects by the administration of a mixture of four naked mRNAs encoding an antigen and three additional immunomodulatory molecules; CD40 ligand, constitutive active TLR 4 and CD70, patented as the TriMix mRNA technology by the 'Vrije Universiteit Brussel' (VUB), and licensed to eTheRNA immunotherapies [88]. The TriMix technology is currently under clinical investigation as an mRNA immunotherapeutic for melanoma and breast cancer, where the mixture of naked, unmodified mRNA sequences is respectively delivered i.n. or directly into accessible tumor lesions. Recently, an i.n. administered TriMix mRNA vaccine was shown to be safe and well tolerated in a doseescalation clinical study against HIV-1 infection, while obtaining moderate HIV-specific T cell responses at high doses (total mRNA dose of $1.2 \mathrm{mg}$ ) [89].

\subsection{Advanced delivery systems for mRNA}

\subsubsection{Nanoparticles: opening new avenues}

Despite the successes obtained with naked mRNA, research towards nanoparticle carriers for the delivery of mRNA vaccines was initiated. The rationale behind this, was that mRNA nanomedicines could act as multi-functional agents that widen the options with respect to vaccine delivery. For one, as mRNA within nanoparticles is much better protected against enzymatic degradation conditions, new delivery avenues such as i.v. administration become possible. Furthermore, by formulating mRNA as a nanoparticle, it allows to alter its biodistribution, cellular targeting and cellular uptake mechanism, in such a way that it can contribute to the delivery of mRNA and vaccine's outcome.

Although it is clear that the choice and optimisation of a nanoparticle is essential to achieve successful mRNA transfection, it is important to realize that many studies suggest that the transfection experiments in cultured cells may not reliably predict the in vivo behaviour of mRNA formulations. This glaring discrepancy between the in vitro and in vivo delivery of mRNA was further demonstrated by Bhosle et al., who observed that completely different cellular uptake pathways were involved in vitro and in vivo, and this for both naked mRNA as well as a lipid-based nanoparticle (LNP) containing mRNA [90]. Moreover, using a high throughput system, Paunovska et al. were able to test hundreds of LNPs for the nucleic acid delivery to macrophages or endothelial cells after i.v. delivery, but found almost no in vitro-in vivo correlations [91]. These studies raise the question whether it is entirely Utopian to believe that nanoparticle-based strategies can be rationally designed to fulfil their multi-functional role as mRNA vaccine-enhancing moieties. In the following sections, we will discuss some of the key considerations when designing nanoparticles for mRNA vaccination, with a particular focus on mRNA LNPs, as these have already made it to the (early) stages of clinical testing $[16,92]$. 
For the reader's interest, extensive summaries of the chemically distinct nanoparticle compositions for mRNA delivery including, but not limited to, protamine, lipids or polymers, as well as hybrid formulations can be found elsewhere [38, 93].

\subsubsection{Designing and preparing lipid nanoparticles for mRNA delivery}

The lipid formulations that have been tested for the delivery of mRNA are typically composed of a cationic/ionizable lipid and other "helper" lipids, such as a phospholipid, cholesterol and/or a poly(ethylene glycol) (PEG) lipid (see Figure 4). The cationic lipids are generally included to allow electrostatic complexation of the negatively charged mRNA molecules, and can roughly be subdivided according to the pKa of the amino group into (i) "permanently-charged lipids", such as DOTMA, DOTAP and DC-cholesterol [1, 94, 95], or (ii) " $\boldsymbol{p H}$-dependent ionizable lipids", such as D-Lin-MC3-DMA and the lipid-like molecule C12-200 [96-99]. These ionizable lipids ( $\mathrm{pKa}<7$ ), originally optimized for siRNA delivery, have a neutral to mildly cationic charge under physiological $\mathrm{pH}$ conditions. This offers certain benefits over the permanently-charged lipids, the foremost of which is that ionizable lipids have been associated with a reduced toxicity and a prolonged blood circulation lifetime [100, 101]. The other lipid components are considered "helper lipids", owing to their distinct functional properties which may affect the structural arrangement of the complexed mRNA LNPs to improve their stability or promote the intracellular uptake and cytosolic entry of mRNA (LNPs) [102].

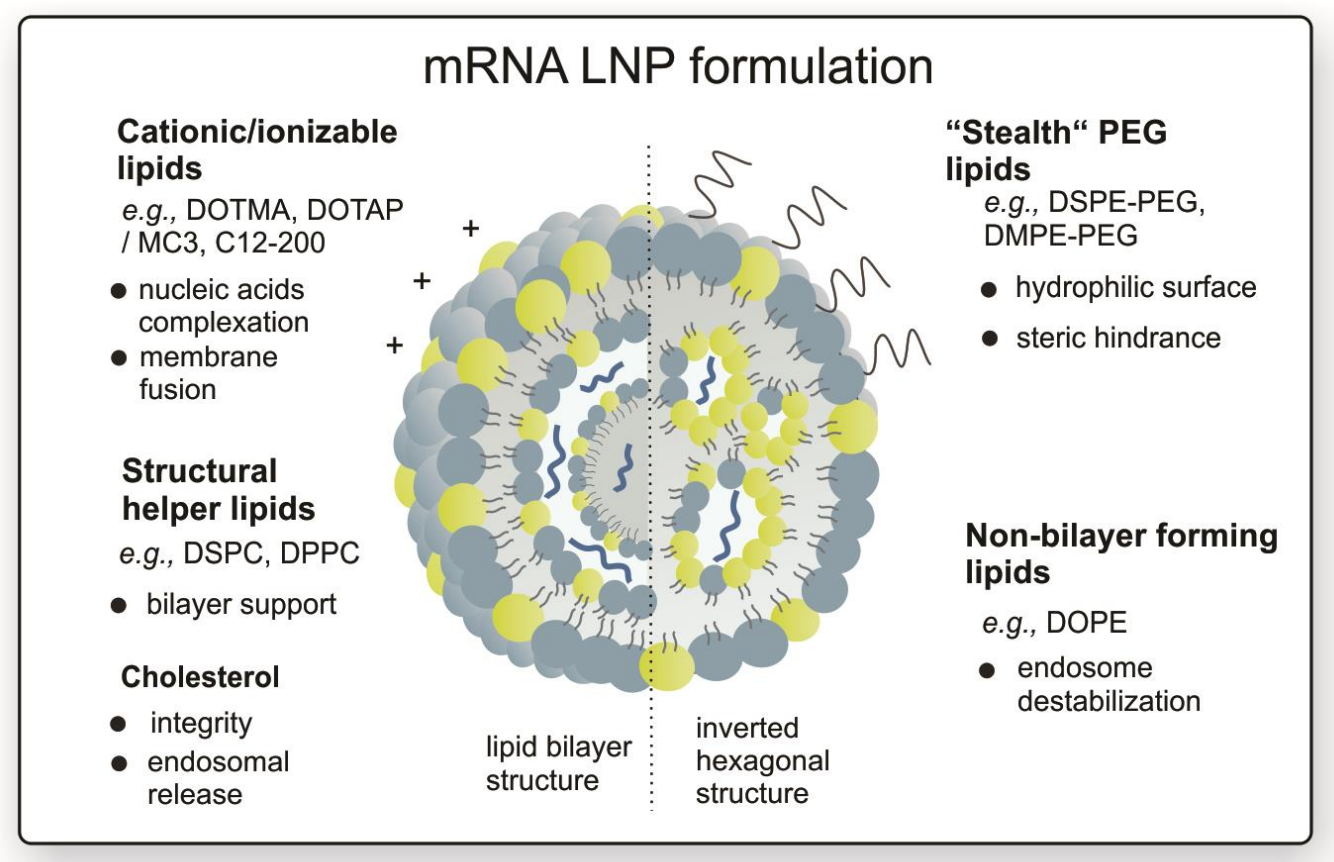

Figure 4. Schematic representation of mRNA lipid nanoparticles. The choice of the amino lipids (cationic or ionizable lipids) and helper lipids will have an impact on the structural arrangement and functional properties of the formulated mRNA LNPs. A proper 
balance needs to be find in order to obtain enough particle stability in a biological context, while inside the target cells the mRNA cargo should be dissociated and the LNPs should promote the endosomal release of mRNA.

One of the key barriers that affects the overall transfection efficiency, is endosomal degradation of the engulfed mRNA LNPs. As a result, a lot of effort is made to modify and optimize candidate mRNA LNPs to facilitate the endosome-to-cytosol transition of the mRNA cargo. The mechanism behind the endosomal release of mRNA was suggested to depend on a lipidmixing step of the LNPs' protonated ("ionized") lipids and anionic phospholipids of the endosomal membrane [103-105]. The ion pair formation between these lipids would trigger a membrane fusion and membrane destabilization, which in turn enhances the escape of mRNA molecules from the endosomes. Additionally, this lipid exchange was suggested to induce a non-bilayer structure conversion (i.e. lamellar-to-inverted hexagonal phase), which would dissociate LNPs and support the destabilization of the endosomal membrane [106]. Studies have linked the structural organization of the mRNA and lipid components to the eventual transfection efficiency that can be achieved. Note that the physicochemical and structural characteristics of mRNA LNPs will depend on the lipid composition, the ratio of mRNA to the total amount of (cationic) lipids, and the LNP synthesis (for a detailed review on these parameters also see [107]).

When mRNA LNPs are prepared by admixing mRNA with pre-formed (monolamellar) liposomes containing a permanently-charged lipid, it is assumed that the liposomes reorganize to form a multi-lamellar structure in which mRNA molecules are "sandwiched" in between concentric lipid bilayers [108]. The addition of saturated phospholipids, such as DPPC and DSPC, increases the phase transition temperature of the cationic liposomes and supports the formation of such a lamellar lipid bilayer structure [102]. By contrast, the unsaturated phospholipid DOPE facilitates the formation of a non-lamellar lipid phase (i.e. inverted hexagonal phase), which was found to contribute to the endosomal escape [109]. However, the latter may hold true only in in vitro conditions. In preclinical testing, the incorporation of DOPE was linked to an increased serum-induced disintegration of cationic (DNA) LNPs and thus poor in vivo transfection efficiency [110].

Another mRNA LNP production strategy is ethanol dilution, which is a suitable method for preparing the more technically advanced LNP systems containing ionizable lipids. Here, the individual lipids are dissolved in ethanol, which is then rapidly mixed with mRNA in an acidic aqueous buffer. By diluting the ethanol phase, the lipids undergo a condensation process and form LNPs while efficiently entrapping the mRNA. This is then followed by a dialysis step into neutralizing buffer to remove ethanol and neutralize the $\mathrm{pH}$. The mechanism of the formation of these ionizable LNP systems (with different nucleic acid payloads) has recently been 
elucidated by Kulkarni and colleagues [111, 112]. They proposed that in the rapid-mixing step at acidic pH, ("empty") small liposomal structures and ("loaded") larger electron-dense particles are formed. Next, during the dialysis step these particles undergo fusion as the $\mathrm{pH}$ is neutralized, which generates the final LNP system. Furthermore, they demonstrated that the PEG-lipid content dictates the eventual LNP size by exerting repulsive forces at the particle surface that limits further fusion. In another study, Yanez Arteta et al. indicated that the structural arrangement of mRNA LNPs based on D-Lin-MC3-DMA, DSPC, cholesterol and a PEG-lipid exhibited a disordered inverse hexagonal phase containing D-Lin-MC3-DMA, cholesterol, water and mRNA. This core was surrounded by a lipid monolayer containing mainly the DSPC and DMPE-PEG 2000 content, as well as a fraction of D-Lin-MC3-DMA and cholesterol [113]. Interestingly, by adjusting the molar ratios of the different lipids, the authors could produce mRNA LNPs with varying surface characteristics. They found that LNP compositions that favour a partial segregation of D-Lin-MC3-DMA lipids from the internal core to the outer surface, correlated with an increased transfection efficiency. By contrast, mRNA LNPs with an enriched DSPC content at the surface (approaching an almost pure monolayer of DSPC) exhibited a weak transfection capacity. In addition, the authors suggested that an enrichment of cholesterol might result in the formation of nanocrystals at the LNP surface. Although this was not further investigated in this study, prior reports have linked the occurrence of cholesterol nanocrystals to an improved transfection efficiency [114, 115].

Notably, bench-top microfluidic mixing devices are available for the production of unloaded liposomes or mRNA LNPs via this ethanol-dilution principle, with the potential to be scaled up for clinical or industrial purposes [116]. These microfluidic devices producing LNPs in a wellcontrolled and high-throughput manner have certainly advanced the clinical translation of novel LNPs for gene delivery. Besides facilitating the production process, the rapid screening of novel lipid libraries has helped to continually optimize lipid compositions. Furthermore, this has also supported the discovery of new lead ionizable lipids holding greatly improved potency and safety for mRNA transfection [117-119].

Besides progress in the LNP design and production, novel insights in the mode of action to transfect cells in vivo is crucial for further development. Although the theory of membrane fusion has been around for more than a decade, the mechanism of LNPs to promote the cytosolic delivery of mRNA cannot be reduced to merely this single aspect [120]. More recent studies describe that the endocytic trafficking of mRNA LNPs is a dynamic process, which involves recycling pathways and signalling pathways that affect the cytosolic entry and translation of mRNA. For instance, the transporter Niemann-Pick Type C-1, located on late endolysomes, was found to be responsible for the exocytosis of a large fraction of internalized (si)RNA LNPs, hence strongly reducing the cytosolic delivery [121]. By contrast, the 
recruitment of the mechanistic target of rapamycin complex 1 to the lysosomal membrane was key to trigger the translation of delivered mRNA [122].

Less investigated, but possibly equally important, is the relationship between the mechanism of cellular entry and the intracellular trafficking of mRNA. By targeting mRNA LNPs to selective surface receptors expressed by DCs, the particles may be routed into intracellular trafficking pathways that are less degradative for the mRNA cargo [123]. As such, (mRNA) nanovaccines have been targeted towards the C-type lectins DEC-205, CLEC9A and mannose receptor, which are also involved in pathways that favour the uptake, endocytic protection and crosspresentation of dead cell antigens [124-126].

\subsubsection{The administration of mRNA LNPs}

Another key parameter that will determine the efficacy and safety of mRNA LNPs is the choice of administration route (see Figure 5). Importantly, depending on the administration route, specific extracellular barriers might be encountered which prompts specific particle optimizations. The skin represents a very convenient route, which can result in an immune response by two separate mechanisms: either mRNA LNPs locally transfect and activate APCs which consequently migrate to the lymphatics, or the mRNA LNPs are passively drained via the lymphatic system, thus delivering the mRNA payload directly in close proximity to LNresident APCs and T cells.

In a detailed study in rhesus macaques, Liang et al. investigated the immune cell infiltration, vaccine uptake, immune activation and mRNA translation after either i.m. or i.d. injection of an ionizable LNP formulated with nucleoside-modified mRNA [127]. For both administration routes, they could show a rapid recruitment of neutrophils, monocytes and different DC subsets to the injection site (skin or muscle). Although all of these cell types were able to internalize mRNA LNPs, only monocytes and myeloid DCs showed high translation of the mRNA. In addition, they could detect mature, mRNA-transfected APCs in the draining LNs. With respect to the resulting immune response, they showed that i.d. delivery resulted in an earlier activation of skin DCs and a more efficient migration to draining LNs, as well as a prolonged antigen availability at the injection site. Together, this resulted in a superior immunogenicity compared to i.m. delivery, as i.d. injection resulted in the highest antibody titers and CD4 ${ }^{+} \mathrm{T}$ cell activation. Based on prior reports, particle size is a critical factor to obtain efficient lymphatic transport of nanoparticles. Reports suggest that nanoparticles up to $200 \mathrm{~nm}$ are able to enter the lymphatic vessels, whereas larger particles are withheld at the injection site [128-130]. PEGylation accelerates the drainage of (lipid) nanoparticles into the lymphatic system, while targeting ligands such as mannose and antibodies against selective DC receptors can increase the entrapment of liposomes inside draining LNs [131-133]. In addition, studies suggested that 
PEGylation is required to prevent a complete immobilization of the particles in the extracellular matrix $(E C M)$ of the skin, explained by the fact that ECM components, such as glycosaminoglycans can inhibit both the distribution and cellular uptake of non-PEGylated LNPs at the injection site [134]. To give an example of an optimized mRNA LNP for lymphatic transport, Wang et al. generated a nanoparticle system consisting of a pre-condensed core of mRNA and calcium phosphate, stabilized by DOPA and coated by a lipid shell of DOTAP and DSPE-PEG[135]. These mRNA nanoparticles had a relatively small particle size ( $<50 \mathrm{~nm})$, and an uncharged, strongly PEGylated outer-surface. As such, this system was found to efficiently traffic into the lymphatics, with a detectable mRNA presence in the draining $L N$ as early as $4 \mathrm{~h}$ after s.c. injection, enabling the direct delivery of (almost the complete dose of) mRNA to LNresident macrophages and DCs.

In the specific case of cancer immunotherapy, it was proven essential to evoke a systemic immune response to obtain antitumor immunity, which makes i.v. delivery a highly appealing administration route for mRNA-based cancer vaccines [92, 136, 137]. It is beyond any doubt that particle features such as size, surface charge, and structural conformation might drastically change once the mRNA LNPs enter the bloodstream. Indeed, the interaction of (mRNA) nanoparticles with biological fluids, gives rise to the adsorption of endogenous proteins and other biomolecules to the particular surface, resulting in the formation of a biomolecular or protein corona [138]. This may reduce the colloidal stability of the mRNA LNPs, followed by the aggregation of the particles and a premature release of the mRNA cargo [139, 140]. Therefore, it is good practice to determine the size, stability and mRNA encapsulation efficiency of LNPs in undiluted biological media, using advanced microscopy methods such as fluorescence single particle tracking (fSPT, for LNP size and aggregation) and fluorescence correlation spectroscopy (FCS, to determine the degree of mRNA complexation) [139-141]. It is also possible to tweak the serum stability of LNPs by modifying their helper lipid composition. For one, cholesterol is typically used to increase the rigidity of LNPs (i.e. reducing the permeability of the lipid membrane), and therefore contributes to improved LNP stability and integrity in the presence of serum [110, 142]. Alternatively, the incorporation of PEGylated lipids is widely used to provide a "stealth effect". This reduces the overall protein adsorption, and improves the colloidal stability of LNPs, but also hampers the LNP cellular uptake and transfection capacity [143]. Here, PEG-lipids with shorter acyl chains can provide an efficient strategy to overcome this "PEG-dilemma". These PEG-lipids can gradually diffuse out of the LNPs, and thus temporarily confer stealth properties to the LNP system, while achieving higher transfection efficiencies compared to the longer, persistent PEG-lipids [139, 144].

From another vantage point, the formation of such a biomolecular corona, provides the nanoparticle with new (surface) properties, which could potentially be exploited to target and/or 
enhance delivery $[138,145]$. Importantly, the amount and identity of the individual proteins present in this biomolecular corona will depend on both the ("original") nanoparticle characteristics and its biological context [138]. In general, i.v. injected nanoparticles are known to react with opsonic blood proteins, such as complement fragments, immunoglobulins, and fibronectin, which facilitates uptake by phagocytic cells, hence nanoparticle clearance [146, 147]. Recently, Vu et al. elucidated how nanoparticles mediate complement activation, and found this to be quite universal over a range of clinically approved liposomes [148]. The creation of a biomolecular corona causes the exposure of self-epitopes, to which naturally occurring antibodies can bind. Merely a few surface-bound immunoglobulin molecules are sufficient to trigger complement activation. Several studies suggested that natural opsonisation processes might be manipulated as a passive strategy of targeting APCs [149, 150], or that it is possible to use the complement cascade as a danger signal for vaccination purposes [151]. Others have linked extensive complement activation with idiosyncratic infusion reactions to nanomedicines, clinically manifested as cardiopulmonary distress. However, recent findings suggest that these nanoparticle-mediated infusion reactions are triggered by an acute intoxication of pulmonary intravascular macrophages [152-154].

PEGylation strategies have been used to mitigate the nanoparticle recognition and rapid clearance by phagocytic cells. Schöttler et al. demonstrated that PEGylated nanoparticles evade the macrophage system, not only by lowering the deposition of complement fragments and immunoglobulins on the nanoparticle surface, but rather by a selective higher presence of clusterin that functions as a strong dysopsonin [143]. However, PEGylation also has its limitations: in patients with pre-existing anti-PEG antibodies, infusion of PEGylated LNPs is contra-indicated, as this could lead to an even stronger complement activation as well as an accelerated blood clearance of PEGylated nanoparticles. This warrants precautions for the sensitization to PEG and prompts the investigation of novel "stealth" strategies [143, 148, 155]. It should be noted that detailed studies on the role of the biomolecular corona formation and its dynamics on LNPs are still very limited. However, further progress in this field might discover new insights in the variations that have been found in the biodistribution and cell-specific targeting after the systemic delivery of distinct (mRNA) LNP formulations. As example, Akinc et al. found that the selective adsorption of apolipoprotein $\mathrm{E}$ onto an ionizable (neutral) LNP was responsible for the specific and potent delivery of (si)RNA to hepatocytes through receptor mediated endocytosis [156]. In comparison, cationic mRNA LNPs composed of a cationic lipid and cholesterol, or DOPE were found to primarily target the lungs, where they transfect tissueresident DCs, macrophages and endothelial cells [142, 157, 158]. Interestingly, by lowering the lipid-to-mRNA ratio to a lower lipid content, Kranz et al. demonstrated that DOTMA-DOPE mRNA LNPs become negatively charged and specifically target DCs in the spleen $[92,158]$. 
This finding of specifically targeting anionic mRNA LNPs to the spleen could be confirmed in a patient participating in a phase I trial for melanoma [159]. While it is possible that the observed site-specific targeting could be attributed to the LNP surface charge, the involvement of a different biomolecular corona cannot be excluded. Therefore, a detailed comparison between the biomolecular corona of these differently charged mRNA LNPs could be useful to further elucidate the mechanism behind the observed variety in organ distribution and cell-targeting after i.v. administration.

As mentioned previously, antibodies or other targeting moieties can be incorporated in the LNP system to support selective organ disposition of mRNA LNPs, or to promote receptor-mediated uptake by specific (immune) cell types. To give a few other examples, Parhiz et al. demonstrated that ionizable mRNA LNPs conjugated with antibodies against the vascular cell adhesion molecule, PECAM-1, promoted the mRNA transfection of endothelial cells in the lungs after systemic delivery [160]. Perche et al. prepared mannosylated nanoparticles loaded with mRNA, which could be used as an active targeting strategy to enhance the transfection of splenic DCs [126]. For a more elaborated summary on potential target receptors and technical details on ligand conjugation strategies for mRNA LNPs, we also refer the reader to [123]. Of note, the Dan Peer lab recently proposed a modular targeting platform for the selective delivery of (si)RNA LNPs to diverse leukocytes in vivo. Here, the conjugation of targeting antibodies was based on the incorporation of a lipoprotein inside the LNP system that non-covalently binds to the Fc domain of a selected targeting antibody [161, 162]. However, it should be noted that the incorporation of a targeting ligand adds an extra layer of complexity to the LNP system, involving additional synthetic steps, costs and regulatory hurdles [163]. Moreover, the targeting ability of such functionalized nanoparticles can be overruled by the deposition of endogenous proteins and the passive transport and clearance of nanoparticles [164]. Therefore, the potential clinical benefits of utilizing these targeting moieties for a specific mRNA approach should weigh up the cost of complexity. 


\section{mRNA vaccine delivery}

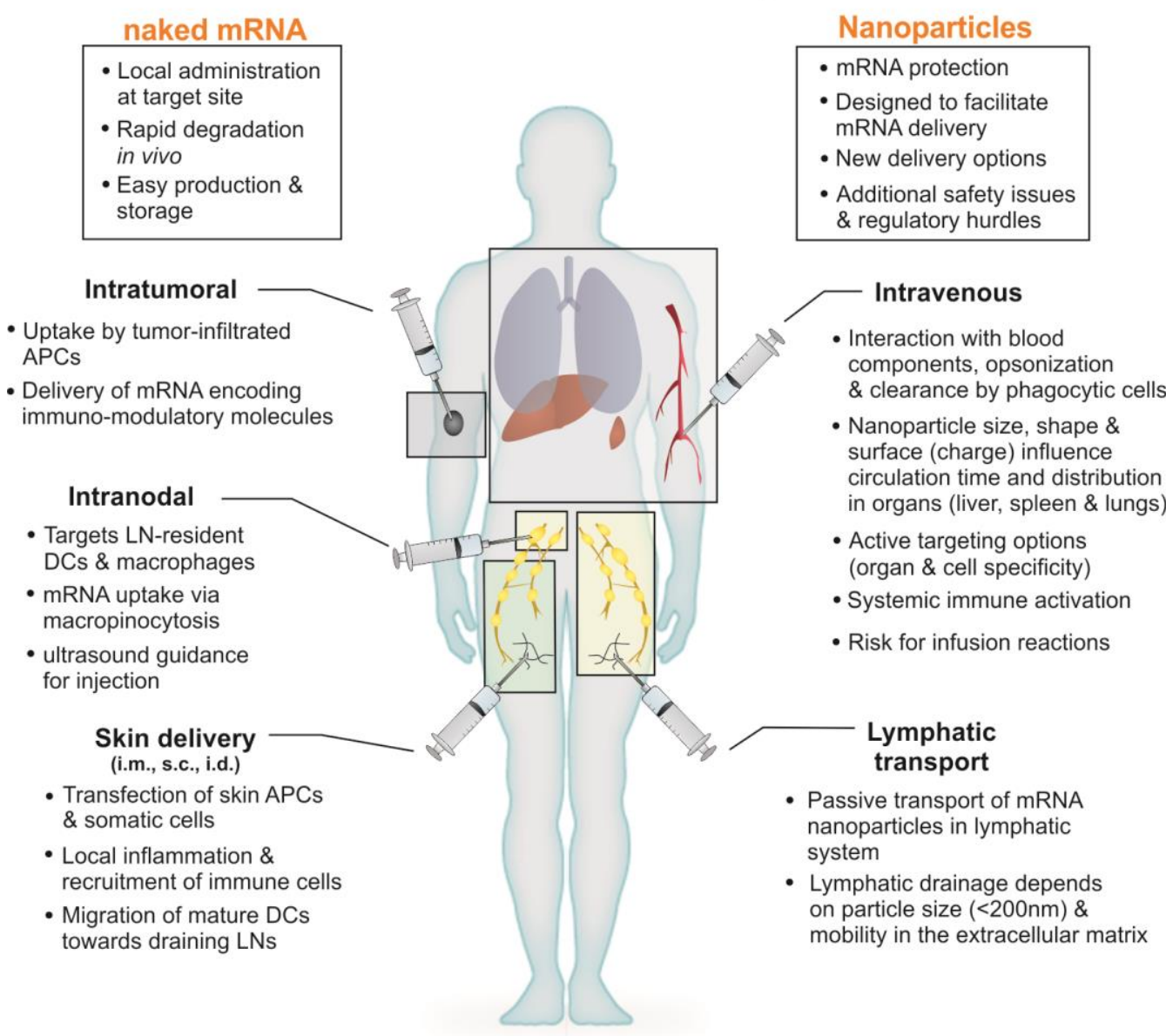

Figure 5. Administration routes for mRNA vaccine delivery. Figure shows mRNA delivery options for both naked mRNA formats and nanoparticle-based strategies.

\section{The "self-adjuvant" effects of mRNA: The Good, the Bad, and the Ugly}

Contradictory results have been reported about the role of type I IFN responses on the immunogenicity of mRNA vaccines (see also section 2.3). A number of reports have revealed that the capacity of mRNA LNPs to evoke CTL responses strongly depended on the production of type I IFNs. Two papers showed that the i.v. administration of unmodified mRNA LNPs triggered a rapid and systemic induction of type I IFNs, which involved the selective targeting of DCs and macrophages and the activation of the TLR7 pathway [92, 136]. Experiments in mice with gene knockouts of the IFN- $\alpha$ receptor 1 (Ifnar $\left.1^{-1-}\right)$ or TLR7 receptor $\left(\mathrm{Tlr} 7^{-{ }^{-}}\right)$ demonstrated that the systemic type I IFN response evoked by mRNA LNPs was crucial to activate APCs and effector cells. Also, antitumor responses in a lung metastasis model were significantly impaired when tumor-bearing mice were immunized i.v. with mRNA LNPs while receiving i.p. injections with anti-IFNAR1 antibodies [92]. Comparative studies performed by our research group and others demonstrated that nucleoside-modified mRNA LNPs 
outperformed unmodified mRNA LNPs in translation capacity, but failed to elicit successful CTL responses due to the drastically reduced production of type I IFNs [119, 157].

Where type I IFN is highly valuable to trigger an effective T cell response, other papers showed that an early type I IFN response inhibits the expression of antigen-encoding mRNA, which was rather detrimental for the mRNA vaccine's outcome [165-167]. De Beuckelaer and colleagues demonstrated that the efficacy to evoke (CTL) antitumor immune responses in a B16 melanoma model of s.c. or i.d. administered DOTAP-DOPE mRNA LNPs, was strongly increased after type I IFN blockade [165]. For a self-amplifying mRNA LNP vaccine, Pepini et al. reported that the antigen expression was dramatically enhanced in the absence of IFN- $\alpha / \beta$, which correlated with improved immunogenicity and IgG antibody responses [167]. Additionally, the robust and sustained antigen expression of nucleoside-modified mRNA was associated with more optimal antibody responses compared to unmodified mRNA [12, 13].

Clearly, this raises the fundamental question how to deal with the self-adjuvanticity of mRNA vaccines. In general, acute type I IFN responses mediate pleotropic and pro-inflammatory effects in both innate and adaptive immune cells [36, 168-171]. Indeed, type I IFN signalling induces DC maturation, improved antigen processing and presentation, and enhances DC migration to enriched T cell zones (e.g., via CCR7) [172-175]. Importantly, type I IFNs directly act as a signal 3 cytokine for $\mathrm{T}$ cell activation, promoting the clonal expansion, survival and effector differentiation of both CTLs and T helper cells [168, 172, 176]. In humoral immunity, type I IFNs promote the generation of long-lived antibody responses by the indirect enhancement of helper $T$ cell responses and by direct immune-stimulatory effects on $B$ cells $[177,178]$. By regulating other pro-inflammatory cytokines, type I IFNs are also involved in the regulation of other immune cell types, such as Natural Killer (NK) cell responses [179].

Lessons could potentially be learned from the detrimental role of type I IFNs during persistent viral infections. Here, it was found that chronic activation of the type I IFN pathway leads to the induction of regulatory DCs, the deletion of virus-specific B cells and strongly impaired T cells responses [180-182]. In an opinion article, De Beuckelaer et al. suggested that the type I IFN response by mRNA vaccines might have dual effects on naïve $T$ cells, depending on the duration and relative timing between type I IFN signalling and T cell priming [169]. If type I IFNs are produced after recognition of MHC-presented antigens by T cells, they act as a strong $3^{\text {rd }}$ signal cytokine to stimulate $T$ cell activation and proliferation. By contrast, in case of a different timeframe, where the interaction between APCs and T cells is delayed or even absent, type I IFNs have completely opposite effects: rather than stimulating $T$ cells, they activate an antiproliferative and pro-apoptotic programme [168]. This might explain why the early type I IFN response induced by an mRNA vaccine, might not only limit the mRNA-encoded antigen expression, but even exert deleterious effects on T cell responses [169]. 
The involvement of type I IFNs in the regulation of immune tolerance, which can promote the development of autoreactive B cells and T cells, poses an even greater threat [183-185]. This can lead to severe autoimmune consequences, such as systemic lupus erythematosus and diabetes. As first clinical results with different mRNA vaccines have now been published, we learn more about their efficacy and potential side effects in humans, as summarized in Table 1 and also reviewed in [38, 186]. Although the numbers of patients are still limited, Pardi et al. stated that some of the observed side effects of the clinically-tested mRNA vaccines might not be considered trivial, including the potential risks for autoimmune diseases [186]. In a phase I/Ila trial of a RNactive ${ }^{\circledR}$-based vaccine for non-small cell lung carcinoma (NSCLC), common diagnostic indicators for autoimmunity were found to be elevated up to $20 \%$ of the patients after a RNactive ${ }^{\circledR}$ schedule of five intradermal injections (dose of 400-1600 $\mu \mathrm{g}$ ) [187]. Another study testing the safety and immunogenicity of the RNactive ${ }^{\circledR}$ platform as prophylactic vaccine against rabies, elicited a moderate case of Bell's palsy one week after a second i.m. administration of the highest dose of $640 \mu \mathrm{g}$ (1/37 patients). This is a condition of temporary facial paralysis, which has been linked to autoimmunity [188].

How this complexity of type I IFN signalling on both efficacy and safety exactly relates to the design of an mRNA vaccine, requires further investigations. There is, however no doubt that distinct mRNA vaccines, varying in mRNA design, formulation and administration route, will exhibit differences in kinetics and cell-specificity for both mRNA expression and innate immune activation. Alterations in these mRNA vaccine parameters are therefore expected to impact on the role of type I IFN signalling on the mRNA vaccine's outcome, thus deciding if it is good, bad, or ugly. Playing the devil's advocate, it might also be possible that the induction of antibody responses versus CTL responses demands a shifted balance between the translation efficiency and type I IFN activity of mRNA vaccines, which might explain why unmodified mRNA vaccines were found to be more optimal to induce CTL responses, whereas superior antibody responses were detected for nucleoside-modified mRNA vaccines. Nevertheless, it can be expected that an mRNA vaccine that achieves high and sustained antigen availability, will benefit the magnitude and duration of both $T$ cell and $B$ cell responses [11, 189-191].

Excitingly, new imaging tools have been implemented in the evaluation of novel mRNA delivery systems, which allows visualization of mRNA pharmacology at the single cell and tissue level. This includes the generation of transgenic reporter mouse strains, such as the IFN- $\beta$ reporter mice and Cre recombinase (mRNA) reporter mice, as well as the development of fluorescent imaging mRNA probes that allow to detect mRNA at high resolution [90, 158, 192-195]. To give an outstanding example, the Santangelo lab combined the delivery of fluorescentlylabelled mRNA with proximity-based assays [195]. As such, they were able to simultaneously detect cell-specific uptake, translation and in situ activation of the TLR7, RIG-I, MDA5 
pathways upon the delivery of naked- or LNP formulated mRNA in the muscle of mice [194]. These different tools by which mRNA activities can be followed in real time, will be very helpful to identify differences between distinct mRNA vaccine platforms and to compare immunization routes. In combination with immunological read-outs and thorough safety assessments, this will support the development of more effective and safe mRNA vaccines.

\section{Beyond the type I IFN response}

Taking the dichotomous role of the anti-mRNA type I IFN response into account, we hypothesized that it could be of benefit to uncouple the translation and type I IFN activities of mRNA vaccines, and to replace the type I IFN response by another, more controllable immune activation. This strategy provides the freedom to optimize the mRNA construct to a high translation capacity, e.g., using nucleoside-modified mRNA, while chosing a "smarter" immune adjuvant: one that does not interfere with the mRNA translation process and that strongly contributes to effective but controllable immune responses. In a proof-of-concept study, we demonstrated that nucleoside-modified mRNA can be co-delivered with the clinically approved TLR agonist MPLA, achieving functional CTL responses like unmodified mRNA, but with strongly reduced type I IFN responses [157]. Additionally, we optimized a novel mRNA LNP platform which combines the in vivo delivery of nucleoside-modified mRNA and the Natural Killer T (NKT) cell ligand $\alpha$-Galactosylceramide, named as mRNA Galsomes. By the dual "antigen" signalling to both conventional T cells and NKT cells, mRNA Galsomes were able to induce a relatively higher tumor influx of antigen-specific CTLs, NKT and NK cells, as well could reduce the tumor presence of immunosuppressive myeloid cells, compared to mice treated with type I IFN inducing LNPs formulated with unmodified mRNA [196].

Besides this replacement of the type I IFN response by a more controllable immunostimulation, specific strategies are being developed within the framework of immunotherapy where avoiding the type I IFN response to ensure high protein expression, is beneficial. A first alternative to the de novo priming of adaptive immune cells, is to explore passive immunization approaches by using mRNA that directly encodes different antibody formats, including monoclonal antibodies, antibody fragments or bi-specific antibodies [197-200]. As the liver is the main target for many formulations after systemic delivery, this organ has been used as a biofactor for the production and secretion of mRNA-encoded proteins into the systemic. To give two examples, Thran et al. evaluated an LNP formulation of sequence-engineered mRNA coding for prophylactic or therapeutic antibodies. This could provide protection against rabies infection, botulinum intoxication, and tumors [201]. Stadler et al. designed mRNA constructs that encode bispecific antibodies directed against the $T$ cell receptor associated molecule CD3 and tumor antigens, referred to as RiboMABs [197]. This mRNA platform represented a valid 
alternative to classic mRNA cancer vaccines, providing a strong infiltration of $\mathrm{T}$ cells able to eliminate tumors in mice. A second option, is to deliver mRNA encoding immunomodulatory molecules directly at the tumor site, such as cytokines and co-stimulatory molecules. Breckpot and colleagues demonstrated the reprogramming of DCs after the intratumoral administration of TriMix mRNA (i.e. CD40L, caTLR4 and CD70), or using mRNA encoding a fusokine consisting of IFN- $\beta$ and the ectodomain of the TGF- $\beta$ receptor II $[84,202]$. In line with this, Moderna Therapeutics recently published on an anti-cancer immunotherapy, using direct intratumoral- and LNP-mediated delivery of a mixture of mRNA encoding IL-23, IL-36y, and OX40(L) ligand [203]. By the localized expression of these immunomodulatory molecules, this strategy was able to break DC tolerance and to activate tumor-specific $T$ cell responses. Furthermore, Van Hoecke et al. showed that established tumors could be turned into an in situ vaccine, mediated by electroporating tumors with mRNA that codes for the mixed lineage kinase domain-like (MLKL) protein [204]. Indeed, the expression of the MLKL provokes a type of immunogenic cell death, called necroptosis, which enables the release of tumor-specific antigens and natural DAMPs that trigger antitumor responses. 
Table 1: Clinical trials of mRNA vaccines with published (interim or complete) results

$\begin{array}{llll}\text { Clinical trial } & \text { Antigen } & \text { Administration } & \text { Safety }\end{array}$

\section{CureVac's clinical trial results of mRNA vaccine platforms}

Naked,
unmodified
mRNA
$(+$ GM-CSF $)$

Melanoma [205]

(15 patients, phase I) NCT00204516

Renal cell carcinoma $[206,207]$

(30 patients, phase $\mathrm{I} / \mathrm{II}$ )

Protamine-
stabilized
mRNA
(+GM-
CSF/KLH)

Melanoma [208]

(21 patients, phase $\mathrm{I} / \mathrm{II}$ ) NCT00204607

$\begin{array}{cc}\begin{array}{c}\text { Autologous } \\ \text { tumor } \\ \text { antigen }\end{array} & \text { Intradermal } \\ & 200 \mu \mathrm{g} \mathrm{(10x)} \\ \begin{array}{c}6 \text { different } \\ \text { tumor } \\ \text { antigens }\end{array} & 300 \mu \mathrm{g}(5-11 \mathrm{x})\end{array}$

6 different

tumor

antigens

Intradermal

$640 \mu g(12 x)$
Grade I/II: skin

reactions $90 \%$, pain

$49 \%$, fatigue $37 \%$,

fever $12 \%$
Grade I/II: skin reactions, fever, headache

\section{Grade I/II: skin} reactions $50 \%$ grade II, and $40 \%$ grade I, fatigue $86 \%$,pain $50 \%$, headache $50 \%$, fever $40 \%$

4 prostate
antigens

Non small cell lung carcinoma [187, 210] (46 patients, phase I/II) NCT00923312

(26 patients, phase lb in combination with local radiotherapy) NCT01915524

Rabies [17]

(101 subjects, phase I) NCT02241135

\author{
Different \\ Tumor \\ antigens
}

rabies virus glycoprotein
Intradermal 256-1280 $\mu \mathrm{g}$ (2$5 x)$

Intradermal 400-
$1600 \mu \mathrm{g}(5 \mathrm{x})$

Intradermal or intramuscular (needle syringe vs needle-free devices) $80-640 \mu \mathrm{g}(3 \mathrm{x})$
- Grade I/II: erythema

$61 \%$, injection site reaction $48 \%$, fatigue $18 \%$, fever $16 \%$, chills $13 \%$ and influenza-like illness 11\% - Grade III 11\%; urinary retention, anemia, hematuria

- Grade I/II: in most patients

- Grade III 33\%, mostly not drug-related - Serious AE 15\%, but not considered drugrelated

- Positive levels of diagnostic autoimmune markers 20\%

- Injection site reactions (grade I/II)

- Systemic adverse events, including grade III events

- A case of transient, moderate Bell's palsy
-No evidence of clinical effectiveness

- Induction of T cells - Long-term survival correlates with immune responses

- Induction of T cell response in subset of patients

- reduced regulatory $T$ cells

- 1 CR of lung metastases after continuous treatment

- T cell responses in $76 \%$ of evaluable patients - 1 patient with PSA response

- T cell responses in $<30 \%$ of patients

- Antigen-specific humoral responses: $47 \%$ -Increase in $\lg D^{+}$CD38 $8^{\text {hi }} B$ cells, not related to antigenspecific responses

- No objective tumor responses

- Protective antibody titers in $71 \%$ (i.d.) and $46 \%$ (i.m.) of vaccinated persons, after 3 injections via needle-free device

\section{BioNTech clinical trial results of mRNA vaccine platforms}

\section{Naked, unmodified mRNA}

\author{
Melanoma [15] \\ (5 patients, \\ phase I) \\ NCT02035956
}

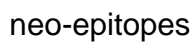

Intranodal

500 or $1000 \mu \mathrm{g}$

(8x)

\author{
- Induction of T cells \\ (against $60 \%$ of the \\ predicted neo-epitopes) \\ - 1 CR in combination with \\ anti-PD-1 treatment
}




$\begin{array}{cccccc}\text { LNPs with } & \text { Melanoma [92] } & 4 \text { different } & \text { Intraveneous } & \text { No safety data } & \text { - IFN- } \alpha \text { and antigen-specific } \\ \text { unmodified } & \text { (data of 3 patients, } & \text { tumor } & 7.2-29 \mu \mathrm{g} & \text { reported } & \text { T cell responses } \\ \text { mRNA } & \text { phase I) } & \text { antigens } & (5-6 \mathrm{x}) & & \\ & \text { NCT02410733 } & & & \end{array}$

\section{Moderna Therapeutics clinical trial results of mRNA vaccine platforms}

\begin{abstract}
LNPs with
nucleoside-

modified

mRNA
\end{abstract}

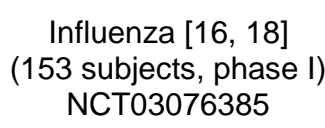

Influenza [16, 18]

(153 subjects, phase I) NCT03076385

Influenza [18]

(120 subjects, phase I)

NCT03345043

$\begin{array}{cc}\text { HA antigen } & \text { Intramuscular } \\ \text { (H10N8) } & 25-400 \mu \mathrm{g}(1-2 \mathrm{x}) \\ & \text { Intradermal } \\ & 25-50 \mu \mathrm{g}(1-2 \mathrm{x})\end{array}$

HA antigen

(H7N9)

Intramuscular

10,25 and $50 \mu \mathrm{g}$

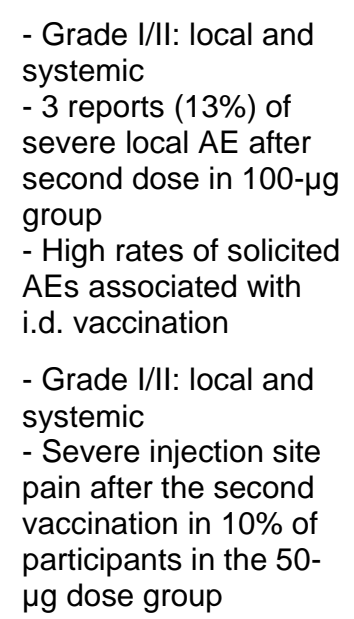

- Grade I/II: local and

stemic

severe local AE after second dose in $100-\mu \mathrm{g}$

AEs associated with

$(1-2 x)$
Immunogenicity after two

i.m. injection of $100 \mu \mathrm{g}$

mRNA dose:

- HAl titers $\geq 40$ in $100 \%$ of

subjects (four times more than baseline).

- $\mathrm{MN} \geq 20$ in $87 \%$

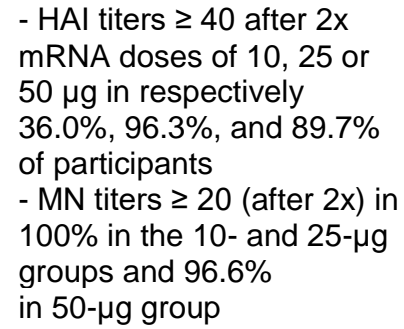

\section{eTheRNA clinical trial results of mRNA vaccine platforms}

\begin{tabular}{|c|c|c|c|c|c|}
\hline $\begin{array}{c}\text { Naked } \\
\text { unmodified } \\
\text { mRNA + } \\
\text { TriMix RNA }\end{array}$ & $\begin{array}{c}\text { HIV-1 [89] } \\
\text { (21 patients, phase I) } \\
\text { NCT02413645 }\end{array}$ & $\begin{array}{c}\text { HTI } \\
\text { sequence } \\
\text { (critical HIV- } \\
1 \text { epitopes) }\end{array}$ & $\begin{array}{c}\text { Intranodal } \\
100-1200 \mu \mathrm{g}(3 \mathrm{x})\end{array}$ & $\begin{array}{l}31 \text { grade } \mathrm{I} / \mathrm{II} \text { and } 1 \\
\text { grade III } \mathrm{AE} \text {, mostly not } \\
\text { considered as drug- } \\
\text { related }\end{array}$ & $\begin{array}{l}\text {-moderate HIV-specific T } \\
\text { cell responses at highest } \\
\text { dose }\end{array}$ \\
\hline
\end{tabular}

NCT, National Clinical Trial; AE, adverse events; CR, complete response; KLH, keyhole limpet hemocyanin, PSA, prostate specific antigen; $\mathrm{HA}(\mathrm{I})$, hemagglutinin (inhibition); MN, microneutralization.

\section{Combination of mRNA cancer vaccines with checkpoint therapies}

For mRNA therapeutics in oncology or for cancer vaccines in general, it might not be enough to activate effector immune responses against cancer. In addition, it is of crucial importance to keep a close eye on several immunosuppressive mechanisms that might hamper the evoked immunity. Upon the activation of T cells, the expression of checkpoint molecules forms a strong negative feedback loop to maintain $T$ cell responses within a desired physiologic range. Overall, the immune system should rapidly act to discontinuities or potential danger, but at the same time an equilibrium should be established that maintains immune homeostasis [211213]. Several studies demonstrated that mRNA cancer vaccines upregulated the expression of the checkpoint molecules programmed death 1 (PD-1) on effector T cells, and its ligand (PD-L1) on tumor cells and APCs [196, 214]. Notably, upregulation of the PD-1/PD-L1 
checkpoint pathway is mainly mediated by IFN-y, as well as can be induced by type I IFN responses [215-217].

As such, this sparks opportunity for combining mRNA vaccines with PD-1 checkpoint inhibitor treatments. Indeed, accumulating pre-clinical evidence shows that $\mathrm{T}$ cell responses and antitumor effects evoked by mRNA cancer therapeutics can strongly be strengthened by combining them with checkpoint inhibitors, such as anti-PD-1(L)-, and also anti-CTLA-4 antibodies [135, 196, 214, 218, 219]. This also translates in the number of clinical trials (phase $\mathrm{l} / \mathrm{llb}$ ) that are ongoing or recruiting patients to test the combination of mRNA vaccination with checkpoint inhibition for different cancer indications. In monotherapy, checkpoint inhibitors have resulted in impressive effects and durable responses in patients with highly refractory and late-stage cancers, such as metastatic melanoma and non-small cell lung cancer (NSCLC) [216]. However, only a subset of the patients benefits from these checkpoint therapies. Therefore, the establishment of effective combination therapies that could increase the response rate of checkpoint inhibitors is an area of intensive investigation [220, 221]. While (some) mRNA cancer vaccines have failed before to obtain objective clinical responses, the combination of these mRNA platforms with checkpoint inhibitors might represent a valuable approach (i) to ensure the longevity and continued effectiveness of the induced antitumor immunity and (ii) to contribute to a T cell inflamed tumor phenotype, rendering a larger group of patients responsive to checkpoint inhibition therapy.

\section{Conclusions and perspectives}

Starting from the earliest publications on the in vivo delivery of mRNA, this nucleic acid represents a versatile and promising platform for vaccination. In this review, we highlighted and explored the two key factors that can determine the mRNA vaccine's chances of success. Firstly, it is essential to ensure adequate intracellular delivery of mRNA molecules, preferably by targeting APCs in vivo. Over the years, a fairly large knowledge gap about the in vivo behaviour of mRNA has been filled, both after the delivery of naked mRNA or when formulated in nanoparticles, and this for various immunization routes. Nowadays, there appears to be a trend towards the use of lipid-based nanoparticles for both localized and systemic delivery of mRNA. We discussed that the design of these LNPs asks for a multi-objective solving approach in which the overall mRNA transfection capacity will depend on trade-offs between different requirements to cross the extra- and intracellular barriers, while precautions are needed to prevent potential nanoparticle inherent (immune) toxicities. For clinical translation of these mRNA LNP systems, it will also be critical to meet pharmaceutical- and regulatory product requirements, going from scale-up manufacturing under GMP conditions, quality control of these products, stability testing, and good safety and efficacy assessments during 
the pre-clinical stage in relevant animal models. Of note, the first approval by the FDA and EMA of an siRNA therapeutic (Onpattro ${ }^{\mathrm{TM}}$ ), utilizing an ionizable LNP technology for parental siRNA administration, may hopefully also serve as a seminal reference work for the future of mRNA vaccines.

A second hard-to-find balance is the one between the mRNA-encoded antigen expression and adequate immunostimulation. Both parameters are of crucial importance to the vaccine outcome, but are inherently linked to the structural properties of the mRNA molecule itself. More specifically, although the mRNA-induced type I IFN response might add to the immunogenicity of the mRNA vaccine, it also interferes with the mRNA-encoded antigen expression and possibly even lead to deleterious immune effects. Fundamental research should further focus on how to control the type I IFN activity of mRNA vaccines, which might vary depending on the mRNA formulation, administration route, the individual patient and the intended therapeutic application. As such, mRNA approaches which do not necessarily rely on the self-adjuvant effect of mRNA are one the rise, such as the replacement of type I IFN responses by more controllable adjuvant systems, or using mRNA for passive immunization approaches. The question whether these novel strategies might offer benefits over the "conventional" mRNA vaccines is a topic worthy of further exploration.

These are exciting times with different biotech companies bringing mRNA therapeutics towards clinical translation. In the near future, mRNA cancer vaccines targeting mutation-derived epitopes (neoantigens) might become an attractive alternative to other clinically-advanced cancer vaccines, such as those composed with synthetic (long) peptides and immune adjuvants [222-224]. Here, it can be expected that the future clinical trials testing the combination of (personalized) mRNA cancer vaccines with checkpoint inhibition will have a better chance for success, however, the safety and optimization of such combination therapies will be another topic of investigation. For prophylactic mRNA vaccines against infectious diseases, (pre-)clinical studies (in non-human primates) show accumulating evidence that mRNA vaccination is feasible, generally well-tolerated, and potentially beneficial over other traditional vaccine approaches. However, it is still waiting for a more extended clinical experience on how patients respond to mRNA vaccines, including more comparative research to select for the best suited mRNA platform and administration route, as well as to show clear therapeutic benefits over other vaccine strategies. Together, it is but a matter of time before we will be able to determine which of these mRNA vaccine candidates/strategies enable effective but safe immune responses in humans, hopefully leading to a new generation of vaccines.

\section{Acknowledgements}


$\mathrm{H}$. Dewitte is a postdoctoral fellow of the Research Foundation-Flanders, Belgium (FWOVlaanderen; grant No. 12E3916N). This research is supported by the FWO grant No. G040319N and the Flemish agency for Innovation trough Science and Technology (IWT SBO NanoComit).

\section{References}

[1] R.W. Malone, P.L. Felgner, I.M. Verma, Proc. Natl. Acad. Sci. U.S.A., 86 (1989), pp. 60776081.

[2] J.A. Wolff, R.W. Malone, P. Williams, W. Chong, G. Acsadi, A. Jani, et al., Science (New York, N.Y.), 247 (1990), pp. 1465-1468.

[3] F. Martinon, S. Krishnan, G. Lenzen, R. Magne, E. Gomard, J.G. Guillet, et al., Eur. J. Immunol., 23 (1993), pp. 1719-1722.

[4] R.M. Conry, A.F. LoBuglio, M. Wright, L. Sumerel, M.J. Pike, F. Johanning, et al., Cancer Res., 55 (1995), pp. 1397-1400.

[5] M.C. Nussenzweig, R.M. Steinman, B. Gutchinov, Z.A. Cohn, J. Exp. Med., 152 (1980), pp. 1070-1084.

[6] R.M. Steinman, Z.A. Cohn, J. Exp. Med., 137 (1973), pp. 1142-1162.

[7] R.M. Steinman, G. Kaplan, M.D. Witmer, Z.A. Cohn, J. Exp. Med., 149 (1979), pp. 1-16.

[8] R.M. Zinkernagel, P.C. Doherty, Nature, 248 (1974), pp. 701.

[9] A.M. Van Nuffel, D. Benteyn, S. Wilgenhof, L. Pierret, J. Corthals, C. Heirman, et al., Mol. Ther., 20 (2012), pp. 1063-1074.

[10] A. Bonehill, C. Heirman, S. Tuyaerts, A. Michiels, K. Breckpot, F. Brasseur, et al., J. Immunol., 172 (2004), pp. 6649-6657.

[11] H.H. Tam, M.B. Melo, M. Kang, J.M. Pelet, V.M. Ruda, M.H. Foley, et al., Proc. Natl. Acad. Sci. U.S.A., 113 (2016), pp. E6639-E6648.

[12] N. Pardi, M.J. Hogan, M.S. Naradikian, K. Parkhouse, D.W. Cain, L. Jones, et al., J. Exp. Med., 215 (2018), pp. 1571-1588.

[13] G. Lindgren, S. Ols, F. Liang, E.A. Thompson, A. Lin, F. Hellgren, et al., Front. Immunol., 8 (2017), pp. 1539.

[14] U. Sahin, O. Tureci, Science (New York, N.Y.), 359 (2018), pp. 1355-1360.

[15] U. Sahin, E. Derhovanessian, M. Miller, B.P. Kloke, P. Simon, M. Lower, et al., Nature, 547 (2017), pp. 222-226.

[16] K. Bahl, J.J. Senn, O. Yuzhakov, A. Bulychev, L.A. Brito, K.J. Hassett, et al., Mol. Ther., 25 (2017), pp 1316-1327

[17] M. Alberer, U. Gnad-Vogt, H.S. Hong, K.T. Mehr, L. Backert, G. Finak, et al., Lancet, 390 (2017), pp. 1511-1520. 
[18] R.A. Feldman, R. Fuhr, I. Smolenov, A. Ribeiro, L. Panther, M. Watson, et al., Vaccine, 37 (2019), pp. 3326-3334.

[19] N. Pardi, M.J. Hogan, R.S. Pelc, H. Muramatsu, H. Andersen, C.R. DeMaso, et al., Nature, 543 (2017), pp. 248-251.

[20] N. Pardi, A.J. Secreto, X. Shan, F. Debonera, J. Glover, Y. Yi, et al., Nat. Commun., 8 (2017), pp. 14630.

[21] J.S. Chahal, O.F. Khan, C.L. Cooper, J.S. McPartlan, J.K. Tsosie, L.D. Tilley, et al., Proc. Natl. Acad. Sci. U.S.A., 113 (2016), pp. E4133-4142.

[22] M. Meyer, E. Huang, O. Yuzhakov, P. Ramanathan, G. Ciaramella, A. Bukreyev, J. Infect. Dis., 217 (2018), pp. 451-455.

[23] N. Pardi, C.C. LaBranche, G. Ferrari, D.W. Cain, I. Tombácz, R.J. Parks, et al., Mol. Ther. Nucleic Acids, 15 (2019), pp. 36-47.

[24] S. John, O. Yuzhakov, A. Woods, J. Deterling, K. Hassett, C.A. Shaw, et al., Vaccine, 36 (2018), pp. 1689-1699.

[25] C.A. Janeway, Jr., Cold Spring Harbor symposia on quantitative biology, 54 Pt 1 (1989), pp. 1-13.

[26] P. Matzinger, Annu. Rev. Immunol., 12 (1994), pp. 991-1045.

[27] B. Lemaitre, E. Nicolas, L. Michaut, J.M. Reichhart, J.A. Hoffmann, Cell, 86 (1996), pp. 973-983.

[28] A. Poltorak, X. He, I. Smirnova, M.Y. Liu, C. Van Huffel, X. Du, et al., Science (New York, N.Y.), 282 (1998), pp. 2085-2088.

[29] A. Isaacs, R.A. Cox, Z. Rotem, Lancet, 2 (1963), pp. 113-116.

[30] F. Heil, H. Hemmi, H. Hochrein, F. Ampenberger, C. Kirschning, S. Akira, et al., Science (New York, N.Y.), 303 (2004), pp. 1526-1529.

[31] S.S. Diebold, C. Massacrier, S. Akira, C. Paturel, Y. Morel, C. Reis e Sousa, Eur. J. Immunol., 36 (2006), pp. 3256-3267.

[32] K. Kariko, H. Muramatsu, J. Ludwig, D. Weissman, Nucleic acids Res., 39 (2011), p. e142.

[33] K. Kariko, H. Ni, J. Capodici, M. Lamphier, D. Weissman, J. Biol. Chem., 279 (2004), pp. 12542-12550.

[34] M. Yoneyama, M. Kikuchi, T. Natsukawa, N. Shinobu, T. Imaizumi, M. Miyagishi, et al., Nat. Immunol., 5 (2004), pp. 730-737.

[35] J. Devoldere, H. Dewitte, S.C. De Smedt, K. Remaut, Drug discovery today, (2015).

[36] S. Hervas-Stubbs, J.L. Perez-Gracia, A. Rouzaut, M.F. Sanmamed, A. Le Bon, I. Melero, Clin. Cancer Res., 17 (2011), pp. 2619-2627.

[37] U. Sahin, K. Kariko, O. Tureci, Nat. Rev. Drug Discovery, 13 (2014), pp. 759-780.

[38] Z. Zhong, S. Mc Cafferty, F. Combes, H. Huysmans, J. De Temmerman, A. Gitsels, et al., Nano Today, 23 (2018), pp. 16-39. 
[39] K. Kariko, M. Buckstein, H. Ni, D. Weissman, Immunity, 23 (2005), pp. 165-175.

[40] G.K. Koski, K. Karikó, S. Xu, D. Weissman, P.A. Cohen, B.J. Czerniecki, J. Immunol., 172 (2004), pp. 3989-3993.

[41] B.R. Anderson, H. Muramatsu, B.K. Jha, R.H. Silverman, D. Weissman, K. Karikó, Nucleic acids Res., 39 (2011), pp. 9329-9338.

[42] B.R. Anderson, H. Muramatsu, S.R. Nallagatla, P.C. Bevilacqua, L.H. Sansing, D. Weissman, et al., Nucleic acids Res., 38 (2010), pp. 5884-5892.

[43] K. Kariko, H. Muramatsu, F.A. Welsh, J. Ludwig, H. Kato, S. Akira, et al., Mol. Ther., 16 (2008), pp. 1833-1840.

[44] M.S. Kormann, G. Hasenpusch, M.K. Aneja, G. Nica, A.W. Flemmer, S. Herber-Jonat, et al., Nat. Biotechnol., 29 (2011), pp. 154-157.

[45] A.J. Sadler, B.R.G. Williams, Nat. Rev. Immunol., 8 (2008), pp. 559.

[46] T. Schlake, A. Thess, M. Fotin-Mleczek, K.J. Kallen, RNA biology, 9 (2012), pp. 13191330.

[47] H. Goodarzi, H.S. Najafabadi, P. Oikonomou, T.M. Greco, L. Fish, R. Salavati, et al., Nature, 485 (2012), pp. 264.

[48] K.H. Asrani, J.D. Farelli, M.R. Stahley, R.L. Miller, C.J. Cheng, R.R. Subramanian, et al., RNA biology, 15 (2018), pp. 756-762.

[49] G. Kudla, L. Lipinski, F. Caffin, A. Helwak, M. Zylicz, PLoS Biol., 4 (2006), p. e180.

[50] A.G. Orlandini von Niessen, M.A. Poleganov, C. Rechner, A. Plaschke, L.M. Kranz, S. Fesser, et al., Mol. Ther., 271 (2018), pp. 824-836.

[51] F.W. Johanning, R.M. Conry, A.F. LoBuglio, M. Wright, L.A. Sumerel, M.J. Pike, et al., Nucleic acids Res., 23 (1995), pp. 1495-1501.

[52] X. Zhou, P. Berglund, G. Rhodes, S.E. Parker, M. Jondal, P. Liljestrom, Vaccine, 12 (1994), pp. 1510-1514.

[53] A.B. Vogel, L. Lambert, E. Kinnear, D. Busse, S. Erbar, K.C. Reuter, et al., Mol. Ther., 26 (2018), pp. 446-455.

[54] J. Jemielity, T. Fowler, J. Zuberek, J. Stepinski, M. Lewdorowicz, A. Niedzwiecka, et al., RNA, 9 (2003), pp. 1108-1122.

[55] A.N. Kuhn, M. Diken, S. Kreiter, A. Selmi, J. Kowalska, J. Jemielity, et al., Gene Ther., 17 (2010), pp. 961-971.

[56] J. Kowalska, M. Lewdorowicz, J. Zuberek, E. Grudzien-Nogalska, E. Bojarska, J. Stepinski, et al., RNA, 14 (2008), pp. 1119-1131.

[57] S. Holtkamp, S. Kreiter, A. Selmi, P. Simon, M. Koslowski, C. Huber, et al., Blood, 108 (2006), pp. 4009-4017.

[58] Y.H. Chen, J. Coller, Trends Genet., 32 (2016), pp. 687-688. 
[59] N.R. Pamudurti, O. Bartok, M. Jens, R. Ashwal-Fluss, C. Stottmeister, L. Ruhe, et al., Mol. cell, 66 (2017), pp. 9-21 e27.

[60] R.A. Wesselhoeft, P.S. Kowalski, D.G. Anderson, Nat. Commun., 9 (2018), pp. 2629.

[61] J. Li, W. Wang, Y. He, Y. Li, E.Z. Yan, K. Zhang, et al., ACS Nano, 11 (2017), pp. 2531 2544.

[62] B. Scheel, S. Braedel, J. Probst, J.P. Carralot, H. Wagner, H. Schild, et al., Eur. J. Immunol., 34 (2004), pp. 537-547.

[63] B. Scheel, R. Teufel, J. Probst, J.P. Carralot, J. Geginat, M. Radsak, et al., Eur. J. Immunol., 35 (2005), pp. 1557-1566.

[64] R. Heidenreich, E. Jasny, A. Kowalczyk, J. Lutz, J. Probst, P. Baumhof, et al., Int. J. Cancer, 137 (2015), pp. 372-384.

[65] K.J. Kallen, R. Heidenreich, M. Schnee, B. Petsch, T. Schlake, A. Thess, et al., Hum. Vaccines Immunother., 9 (2013), pp. 2263-2276.

[66] D. Weissman, K. Kariko, Mol. Ther., 23 (2015), pp. 1416-1417.

[67] P. Matzinger, Nat. Immunol., 8 (2007), p. 11.

[68] E. Jonasch, F.G. Haluska, Oncologist, 6 (2001), pp. 34-55.

[69] A. Heiser, D. Coleman, J. Dannull, D. Yancey, M.A. Maurice, C.D. Lallas, et al., J. Clin. Invest., 109 (2002), pp. 409-417.

[70] D. Benteyn, C. Heirman, A. Bonehill, K. Thielemans, K. Breckpot, Exp. Rev. Vaccines, 14 (2015), pp. 161-176.

[71] E. Gilboa, J. Vieweg, Immunol. Rev., 199 (2004), pp. 251-263.

[72] M. Bellone, A. Camporeale, A. Boni, J. Immunol., 172 (2004), pp. 2727-2728.

[73] A. Langenkamp, M. Messi, A. Lanzavecchia, F. Sallusto, Nat. Immunol., 1 (2000), pp. 311 316.

[74] S.F. Dowdy, Nat. Biotechnol., 35 (2017), pp. 222-229.

[75] I. Hoerr, R. Obst, H.G. Rammensee, G. Jung, Eur. J. Immunol., 30 (2000), pp. 1-7.

[76] J. Probst, B. Weide, B. Scheel, B.J. Pichler, I. Hoerr, H.G. Rammensee, et al., Gene Ther., 14 (2007), pp. 1175-1180.

[77] C. Lorenz, M. Fotin-Mleczek, G. Roth, C. Becker, T.C. Dam, W.P. Verdurmen, et al., RNA biology, 8 (2011), pp. 627-636.

[78] A. Selmi, F. Vascotto, K. Kautz-Neu, Ö. Türeci, U. Sahin, E. von Stebut, et al., Cancer Immunol., Immunother., 65 (2016), pp. 1075-1083.

[79] A. Kowalczyk, F. Doener, K. Zanzinger, J. Noth, P. Baumhof, M. Fotin-Mleczek, et al., Vaccine, 34 (2016), pp. 3882-3893.

[80] D.K. Edwards, E. Jasny, H. Yoon, N. Horscroft, B. Schanen, T. Geter, et al., J. Transl. Med., 15 (2017), pp. 1. 
[81] S. Kreiter, A. Selmi, M. Diken, M. Koslowski, C.M. Britten, C. Huber, et al., Cancer Res., 70 (2010), pp. 9031-9040.

[82] M. Diken, S. Kreiter, A. Selmi, C.M. Britten, C. Huber, O. Tureci, et al., Gene Ther., 18 (2011), pp. 702-708.

[83] K. Van der Jeught, S. Van Lint, K. Thielemans, K. Breckpot, Oncolmmunology, 4 (2015). [84] S. Van Lint, D. Renmans, K. Broos, L. Goethals, S. Maenhout, D. Benteyn, et al., Cancer immunol. Res., 4 (2016), pp. 146-156.

[85] S. Lazzaro, C. Giovani, S. Mangiavacchi, D. Magini, D. Maione, B. Baudner, et al., Immunology, 146 (2015), pp. 312-326.

[86] P.R. Hess, D. Boczkowski, S.K. Nair, D. Snyder, E. Gilboa, Cancer Immunol., Immunother., 55 (2006), pp. 672-683.

[87] J.P. Carralot, J. Probst, I. Hoerr, B. Scheel, R. Teufel, G. Jung, et al., Cell. Mol. Life Sci., 61 (2004), pp. 2418-2424.

[88] S. Van Lint, C. Goyvaerts, S. Maenhout, L. Goethals, A. Disy, D. Benteyn, et al., Cancer Res., 72 (2012), pp. 1661-1671.

[89] L. Leal, A.C. Guardo, S. Moron-Lopez, M. Salgado, B. Mothe, C. Heirman, et al., AIDS (London, England), 32 (2018), pp. 2533-2545.

[90] S.M. Bhosle, K.H. Loomis, J.L. Kirschman, E.L. Blanchard, D.A. Vanover, C. Zurla, et al., Biomaterials, 159 (2018), pp. 189-203.

[91] K. Paunovska, C.D. Sago, C.M. Monaco, W.H. Hudson, M.G. Castro, T.G. Rudoltz, et al., Nano Lett., 18 (2018), pp. 2148-2157.

[92] L.M. Kranz, M. Diken, H. Haas, S. Kreiter, C. Loquai, K.C. Reuter, et al., Nature, 534 (2016), pp. 396-401.

[93] K.A. Hajj, K.A. Whitehead, Nat. Rev. Materials, 2 (2017), pp. 17056.

[94] D. Simberg, S. Weisman, Y. Talmon, Y. Barenholz, Crit. Rev. Ther. Drug Carrier Syst., 21 (2004), pp. 257-317.

[95] T. Michel, D. Luft, M.K. Abraham, S. Reinhardt, M.L. Salinas Medina, J. Kurz, et al., Mol. Ther.. Nucleic acids, 8 (2017), pp. 459-468.

[96] M. Jayaraman, S.M. Ansell, B.L. Mui, Y.K. Tam, J. Chen, X. Du, et al., Angew. Chem., 51 (2012), pp. 8529-8533.

[97] J.F. Nabhan, K.M. Wood, V.P. Rao, J. Morin, S. Bhamidipaty, T.P. LaBranche, et al., Sci. Rep., 6 (2016), pp. 20019.

[98] K.T. Love, K.P. Mahon, C.G. Levins, K.A. Whitehead, W. Querbes, J.R. Dorkin, et al., Proc. Natl. Acad. Sci. U.S.A., 107 (2010), pp. 1864-1869.

[99] K.J. Kauffman, J.R. Dorkin, J.H. Yang, M.W. Heartlein, F. DeRosa, F.F. Mir, et al., Nano Lett., 15 (2015), pp. 7300-7306.

[100] S. Rietwyk, D. Peer, ACS Nano, 11 (2017), pp. 7572-7586. 
[101] G. Basha, T.I. Novobrantseva, N. Rosin, Y.Y.C. Tam, I.M. Hafez, M.K. Wong, et al., Mol. Ther., 19 (2011), pp. 2186-2200.

[102] X. Cheng, R.J. Lee, Adv. Drug Deliv. Rev., 99 (2016), pp. 129-137.

[103] Y. Xu, F.C. Szoka, Biochemistry, 35 (1996), pp. 5616-5623.

[104] Z. ur Rehman, D. Hoekstra, I.S. Zuhorn, ACS Nano, 7 (2013), pp. 3767-3777.

[105] A. Wittrup, A. Ai, X. Liu, P. Hamar, R. Trifonova, K. Charisse, et al., Nat. Biotechnol., 33 (2015), pp. 870-876.

[106] I.M. Hafez, N. Maurer, P.R. Cullis, Gene Therapy, 8 (2001), pp. 1188.

[107] M.J.W. Evers, J.A. Kulkarni, R. van der Meel, P.R. Cullis, P. Vader, R.M. Schiffelers, Small Methods, 2 (2018), pp. 1700375.

[108] S. Weisman, D. Hirsch-Lerner, Y. Barenholz, Y. Talmon, Biophys. J., 87 (2004), pp. 609614.

[109] H. Farhood, N. Serbina, L. Huang, Biochim. Biophys. Acta, 1235 (1995), pp. 289-295.

[110] S. Li, W.C. Tseng, D.B. Stolz, S.P. Wu, S.C. Watkins, L. Huang, Gene Ther., 6 (1999), pp. 585-594.

[111] J.A. Kulkarni, M.M. Darjuan, J.E. Mercer, S. Chen, R. van der Meel, J.L. Thewalt, et al., ACS Nano, 12 (2018), pp. 4787-4795.

[112] J.A. Kulkarni, D. Witzigmann, J. Leung, R. van der Meel, J. Zaifman, M.M. Darjuan, et al., Nanoscale, 11 (2019), pp. 9023-9031.

[113] M. Yanez Arteta, T. Kjellman, S. Bartesaghi, S. Wallin, X. Wu, A.J. Kvist, et al., Proc. Natl. Acad. Sci. U.S.A., 115 (2018), pp. E3351-E3360.

[114] D. Pozzi, C. Marchini, F. Cardarelli, H. Amenitsch, C. Garulli, A. Bifone, et al., Biochim. Biophys. Acta, 1818 (2012), pp. 2335-2343.

[115] J.L. Betker, M. Kullberg, J. Gomez, T.J. Anchordoquy, Ther. Delivery, 4 (2013), pp. 453462.

[116] A.K.K. Leung, Y.Y.C. Tam, S. Chen, I.M. Hafez, P.R. Cullis, J. Phys. Chem. B, 119 (2015), pp. 8698-8706.

[117] S. Sabnis, E.S. Kumarasinghe, T. Salerno, C. Mihai, T. Ketova, J.J. Senn, et al., Mol. Ther., 26 (2018), pp. 1509-1519.

[118] K.J. Hassett, K.E. Benenato, E. Jacquinet, A. Lee, A. Woods, O. Yuzhakov, et al., Mol. Ther. Nucleic Acids, 15 (2019), pp. 1-11.

[119] M.A. Oberli, A.M. Reichmuth, J.R. Dorkin, M.J. Mitchell, O.S. Fenton, A. Jaklenec, et al., Nano Lett., 17 (2017), pp. 1326-1335.

[120] R.L. Juliano, Nucleic Acid Ther., 28 (2018), pp. 166-177.

[121] G. Sahay, W. Querbes, C. Alabi, A. Eltoukhy, S. Sarkar, C. Zurenko, et al., Nat. Biotechnol., 31 (2013), pp. 653. 
[122] S. Patel, N. Ashwanikumar, E. Robinson, A. DuRoss, C. Sun, K.E. Murphy-Benenato, et al., Nano Lett., 17 (2017), pp. 5711-5718.

[123] K.K. Phua, J. Immunol. Res., 2015 (2015), pp. 680620.

[124] L. Baudino, A. Sardini, M.M. Ruseva, L. Fossati-Jimack, H.T. Cook, D. Scott, et al., Proc. Natl. Acad. Sci. U.S.A., 111 (2014), pp. 1503-1508.

[125] S. Zelenay, A.M. Keller, P.G. Whitney, B.U. Schraml, S. Deddouche, N.C. Rogers, et al., J. Clin. Invest., 122 (2012), pp. 1615-1627.

[126] F. Perche, T. Benvegnu, M. Berchel, L. Lebegue, C. Pichon, P.-A. Jaffrès, et al., Nanomedicine, 7 (2011), pp. 445-453.

[127] F. Liang, G. Lindgren, A. Lin, E.A. Thompson, S. Ols, J. Rohss, et al., Mol. Ther., 25 (2017), pp. 2635-2647.

[128] C. Oussoren, G. Storm, Adv. Drug Delivery Rev., 50 (2001), pp. 143-156.

[129] V. Manolova, A. Flace, M. Bauer, K. Schwarz, P. Saudan, M.F. Bachmann, Eur. J. Immunol., 38 (2008), pp. 1404-1413.

[130] S.T. Reddy, A. Rehor, H.G. Schmoekel, J.A. Hubbell, M.A. Swartz, J. Controlled Release, 112 (2006), pp. 26-34.

[131] Y. Zhuang, Y. Ma, C. Wang, L. Hai, C. Yan, Y. Zhang, et al., J. Controlled Release, 159 (2012), pp. 135-142.

[132] S. Cai, Q. Yang, T.R. Bagby, M.L. Forrest, Adv. Drug Delivery Rev., 63 (2011), pp. $901-$ 908.

[133] M.A. Swartz, J.A. Hubbell, S.T. Reddy, Semin. Immunol., 20 (2008), pp. 147-156.

[134] J.H. van den Berg, K. Oosterhuis, W.E. Hennink, G. Storm, L.J. van der Aa, J.F. Engbersen, et al., J. Controlled Release, 141 (2010), pp. 234-240.

[135] Y. Wang, L. Zhang, Z. Xu, L. Miao, L. Huang, Mol. Ther., 26 (2018), pp. 420-434.

[136] K. Broos, K. Van der Jeught, J. Puttemans, C. Goyvaerts, C. Heirman, H. Dewitte, et al., Mol. Ther.. Nucleic acids, 5 (2016), pp. e326.

[137] M.H. Spitzer, Y. Carmi, N.E. Reticker-Flynn, S.S. Kwek, D. Madhireddy, M.M. Martins, et al., Cell, 168 (2017), pp. 487-502 e415.

[138] M.P. Monopoli, C. Aberg, A. Salvati, K.A. Dawson, Nat. Nanotechnol., 7 (2012), pp. 779 786.

[139] K. Braeckmans, K. Buyens, W. Bouquet, C. Vervaet, P. Joye, F. De Vos, et al., Nano Lett., 10 (2010), pp. 4435-4442.

[140] H. Zhang, S.C. De Smedt, K. Remaut, Acta Biomater., 75 (2018), pp. 358-370.

[141] M. Faria, M. Björnmalm, K.J. Thurecht, S.J. Kent, R.G. Parton, M. Kavallaris, et al., Nat.Nanotechnol., 13 (2018), pp. 777-785.

[142] D. Simberg, S. Weisman, Y. Talmon, A. Faerman, T. Shoshani, Y. Barenholz, J. Biol. Chem., 278 (2003), pp. 39858-39865. 
[143] S. Schottler, G. Becker, S. Winzen, T. Steinbach, K. Mohr, K. Landfester, et al., Nat. Nanotechnol., 11 (2016), pp. 372-377.

[144] F. Shi, L. Wasungu, A. Nomden, M.C. Stuart, E. Polushkin, J.B. Engberts, et al., Biochem. J., 366 (2002), pp. 333-341.

[145] M. Neagu, Z. Piperigkou, K. Karamanou, A.B. Engin, A.O. Docea, C. Constantin, et al., Arch. Toxicol., 91 (2017), pp. 1031-1048.

[146] S.M. Moghimi, D. Simberg, Nano Today, 15 (2017), pp. 8-10.

[147] H.H. Gustafson, D. Holt-Casper, D.W. Grainger, H. Ghandehari, Nano Today, 10 (2015), pp. 487-510.

[148] V.P. Vu, G.B. Gifford, F. Chen, H. Benasutti, G. Wang, E.V. Groman, et al., Nat. Nanotechnol., (2019).

[149] R. Tavano, L. Gabrielli, E. Lubian, C. Fedeli, S. Visentin, P. Polverino De Laureto, et al., ACS Nano, 12 (2018), pp. 5834-5847.

[150] L. Shen, S. Tenzer, W. Storck, D. Hobernik, V.K. Raker, K. Fischer, et al., J. Allergy Clin. Immunol., 142 (2018), pp. 1558-1570.

[151] S.T. Reddy, A.J. van der Vlies, E. Simeoni, V. Angeli, G.J. Randolph, C.P. O'Neil, et al., Nat. Biotechnol., 25 (2007), pp. 1159-1164.

[152] S.M. Moghimi, Drug discovery today, 23 (2018), pp. 1034-1042.

[153] D. Csukás, R. Urbanics, G. Wéber, L. Rosivall, J. Szebeni, Eur. J. Nanomed., 7 (2015), pp. 27-36.

[154] J. Szebeni, Drug discovery today, 23 (2018), pp. 487-492.

[155] P. Grenier, I.M.d.O. Viana, E.M. Lima, N. Bertrand, J. Controlled Release, 287 (2018), pp. 121-131.

[156] A. Akinc, W. Querbes, S. De, J. Qin, M. Frank-Kamenetsky, K.N. Jayaprakash, et al., Mol. Ther., 18 (2010), pp. 1357-1364.

[157] R. Verbeke, I. Lentacker, L. Wayteck, K. Breckpot, M. Van Bockstal, B. Descamps, et al., J. Controlled Release, 266 (2017), pp. 287-300.

[158] S. Rosigkeit, M. Meng, C. Grunwitz, P. Gomes, A. Kreft, N. Hayduk, et al., Mol. Pharmaceutics, 15 (2018), pp. 3909-3919.

[159] S. Pektor, L. Hilscher, K.C. Walzer, I. Miederer, N. Bausbacher, C. Loquai, et al., EJNMMI Res., 8 (2018), p. 80.

[160] H. Parhiz, V.V. Shuvaev, N. Pardi, M. Khoshnejad, R.Y. Kiseleva, J.S. Brenner, et al., J. Controlled Release, 291 (2018), pp. 106-115.

[161] R. Kedmi, N. Veiga, S. Ramishetti, M. Goldsmith, D. Rosenblum, N. Dammes, et al., Nat. Nanotechnol., 13 (2018), pp. 214-219.

[162] N. Veiga, M. Goldsmith, Y. Granot, D. Rosenblum, N. Dammes, R. Kedmi, et al., Nat. Commun., 9 (2018), pp. 4493. 
[163] Z. Cheng, A. Al Zaki, J.Z. Hui, V.R. Muzykantov, A. Tsourkas, Science (New York, N.Y.), 338 (2012), pp. 903-910.

[164] A. Salvati, A.S. Pitek, M.P. Monopoli, K. Prapainop, F.B. Bombelli, D.R. Hristov, et al., Nat. Nanotechnol., 8 (2013), pp. 137.

[165] A. De Beuckelaer, C. Pollard, S. Van Lint, K. Roose, L. Van Hoecke, T. Naessens, et al., Mol. Ther., 24 (2016), pp. 2012-2020.

[166] C. Pollard, J. Rejman, W. De Haes, B. Verrier, E. Van Gulck, T. Naessens, et al., Mol. Ther., 21 (2013), pp. 251-259.

[167] T. Pepini, A.-M. Pulichino, T. Carsillo, A.L. Carlson, F. Sari-Sarraf, K. Ramsauer, et al., J. Immunol., (2017).

[168] J. Crouse, U. Kalinke, A. Oxenius, Nat. Rev. Immunol., 15 (2015), pp. 231-242.

[169] A. De Beuckelaer, J. Grooten, S. De Koker, Trends Mol. Med., 23 (2017), pp. 216-226.

[170] L. Zitvogel, L. Galluzzi, O. Kepp, M.J. Smyth, G. Kroemer, Nat. Rev.. Immunol., 15 (2015), pp. 405-414.

[171] F. McNab, K. Mayer-Barber, A. Sher, A. Wack, A. O'Garra, Nat. Rev. Immunol., 15 (2015), pp. 87-103.

[172] M.P. Longhi, C. Trumpfheller, J. Idoyaga, M. Caskey, I. Matos, C. Kluger, et al., J. Exp. Med., 206 (2009), pp. 1589-1602.

[173] M. Montoya, G. Schiavoni, F. Mattei, I. Gresser, F. Belardelli, P. Borrow, et al., Blood, 99 (2002), pp. 3263-3271.

[174] S. Parlato, S.M. Santini, C. Lapenta, T. Di Pucchio, M. Logozzi, M. Spada, et al., Blood, 98 (2001), pp. 3022-3029.

[175] D.P. Simmons, P.A. Wearsch, D.H. Canaday, H.J. Meyerson, Y.C. Liu, Y. Wang, et al., J. Immunol., 188 (2012), pp. 3116-3126.

[176] M. Wiesel, W. Kratky, A. Oxenius, J. Immunol., 186 (2011), pp. 754-763.

[177] A. Le Bon, G. Schiavoni, G. D'Agostino, I. Gresser, F. Belardelli, D.F. Tough, Immunity, 14 (2001), pp. 461-470.

[178] H. Cucak, U. Yrlid, B. Reizis, U. Kalinke, B. Johansson-Lindbom, Immunity, 31 (2009), pp. 491-501.

[179] J.B. Swann, Y. Hayakawa, N. Zerafa, K.C.F. Sheehan, B. Scott, R.D. Schreiber, et al., J. Immunol., 178 (2007), pp. 7540-7549.

[180] E.B. Wilson, D.H. Yamada, H. Elsaesser, J. Herskovitz, J. Deng, G. Cheng, et al., Science (New York, N.Y.), 340 (2013), pp. 202-207.

[181] I. Osokine, L.M. Snell, C.R. Cunningham, D.H. Yamada, E.B. Wilson, H.J. Elsaesser, et al., Proc. Natl. Acad. Sci. U.S.A., 111 (2014), pp. 7409-7414.

[182] E.A. Moseman, T. Wu, J.C. de la Torre, P.L. Schwartzberg, D.B. McGavern, Sci. Immunol., 1 (2016). 
[183] P.P. Domeier, S.B. Chodisetti, S.L. Schell, Y.I. Kawasawa, M.J. Fasnacht, C. Soni, et al., Cell Rep., 24 (2018), pp. 406-418.

[184] S.R. Walsh, D. Bastin, L. Chen, A. Nguyen, C.J. Storbeck, C. Lefebvre, et al., J. Clin. Invest., 129 (2019), pp. 518-530.

[185] B.S. Marro, S. Legrain, B.C. Ware, M.B.A. Oldstone, JCI Insight, 4 (2019).

[186] N. Pardi, M.J. Hogan, F.W. Porter, D. Weissman, Nat. Rev.. Drug discovery, 17 (2018), pp. 261-279.

[187] M. Sebastian, A. Schroder, B. Scheel, H.S. Hong, A. Muth, L. von Boehmer, et al., Cancer Immunol. Immunother., 68 (2019), pp. 799-812.

[188] A. Greco, A. Gallo, M. Fusconi, C. Marinelli, G.F. Macri, M. de Vincentiis, Autoimmun. Rev., 12 (2012), pp. 323-328.

[189] S.E. Henrickson, T.R. Mempel, I.B. Mazo, B. Liu, M.N. Artyomov, H. Zheng, et al., Nat. Immunol., 9 (2008), pp. 282-291.

[190] S.E. Henrickson, M. Perro, S.M. Loughhead, B. Senman, S. Stutte, M. Quigley, et al., Immunity, 39 (2013), pp. 496-507.

[191] V. Mayya, M.L. Dustin, Trends Immunol., 37 (2016), pp. 513-522.

[192] K.J. Kauffman, M.A. Oberli, J.R. Dorkin, J.E. Hurtado, J.C. Kaczmarek, S. Bhadani, et al., Mol. Ther. Nucleic acids, 10 (2018), pp. 55-63.

[193] K. Van der Jeught, S. De Koker, L. Bialkowski, C. Heirman, P. Tjok Joe, F. Perche, et al., ACS Nano, 12 (2018), pp. 9815-9829.

[194] E.L. Blanchard, K.H. Loomis, S.M. Bhosle, D. Vanover, P. Baumhof, B. Pitard, et al., Mol. Ther.. Nucleic acids, 14 (2018), pp. 52-66.

[195] J.L. Kirschman, S. Bhosle, D. Vanover, E.L. Blanchard, K.H. Loomis, C. Zurla, et al., Nucleic acids Res., (2017).

[196] R. Verbeke, I. Lentacker, K. Breckpot, J. Janssens, S. Van Calenbergh, S.C. De Smedt, et al., ACS Nano, 13 (2019), pp. 1655-1669.

[197] C.R. Stadler, H. Bahr-Mahmud, L. Celik, B. Hebich, A.S. Roth, R.P. Roth, et al., Nat. Medicine, 23 (2017), pp. 815-817.

[198] T. Schlake, A. Thess, M. Thran, I. Jordan, Cell. Mol. Life Sci., 76 (2019), pp. 301-328.

[199] L. Van Hoecke, K. Roose, J. Transl. Med., 17 (2019), pp. 54.

[200] N. Pardi, K. Parkhouse, E. Kirkpatrick, M. McMahon, S.J. Zost, B.L. Mui, et al., Nat. Commun., 9 (2018), pp. 3361.

[201] M. Thran, J. Mukherjee, M. Ponisch, K. Fiedler, A. Thess, B.L. Mui, et al., EMBO Mol. Med., 9 (2017), pp. 1434-1447.

[202] K. Van der Jeught, P.T. Joe, L. Bialkowski, C. Heirman, L. Daszkiewicz, T. Liechtenstein, et al., Oncotarget, 5 (2014), pp. 10100-10113. 
[203] S.L. Hewitt, A. Bai, D. Bailey, K. Ichikawa, J. Zielinski, R. Karp, et al., Sci. Transl. Med., 11 (2019).

[204] L. Van Hoecke, S. Van Lint, K. Roose, A. Van Parys, P. Vandenabeele, J. Grooten, et al., Nat. Commun., 9 (2018), pp. 3417.

[205] B. Weide, J.P. Carralot, A. Reese, B. Scheel, T.K. Eigentler, I. Hoerr, et al., J. Immunother., 31 (2008), pp. 180-188.

[206] S.M. Rittig, M. Haentschel, K.J. Weimer, A. Heine, M.R. Muller, W. Brugger, et al., Oncolmmunology, 5 (2016), pp. e1108511.

[207] S.M. Rittig, M. Haentschel, K.J. Weimer, A. Heine, M.R. Muller, W. Brugger, et al., Mol. Ther., 19 (2011), pp. 990-999.

[208] B. Weide, S. Pascolo, B. Scheel, E. Derhovanessian, A. Pflugfelder, T.K. Eigentler, et al., J. Immunother., 32 (2009), pp. 498-507.

[209] H. Kübler, B. Scheel, U. Gnad-Vogt, K. Miller, W. Schultze-Seemann, F. Vom Dorp, et al., JITC, 3 (2015), pp. 26.

[210] A. Papachristofilou, M.M. Hipp, U. Klinkhardt, M. Früh, M. Sebastian, C. Weiss, et al., JITC, 7 (2019), pp. 38.

[211] P. Matzinger, T. Kamala, Nat. Rev. Immunol., 11 (2011), pp. 221-230.

[212] T. Pradeu, E. Vivier, Sci. Immunol., 1 (2016).

[213] S.C. Wei, C.R. Duffy, J.P. Allison, Cancer discovery, 8 (2018), pp. 1069-1086.

[214] E.J. Sayour, A. Grippin, G. De Leon, B. Stover, M. Rahman, A. Karachi, et al., Nano Lett., 18 (2018), pp. 6195-6206.

[215] D.H. Kaplan, V. Shankaran, A.S. Dighe, E. Stockert, M. Aguet, L.J. Old, et al., Proc. Natl. Acad. Sci. U.S.A., 95 (1998), pp. 7556-7561.

[216] D. Pardoll, Nat. Rev. Cancer, 12 (2012), pp. 252-264.

[217] A.V. Bazhin, K. von Ahn, J. Fritz, J. Werner, S. Karakhanova, Front. Immunol., 9 (2018), pp. 2129-2129.

[218] M. Fotin-Mleczek, K. Zanzinger, R. Heidenreich, C. Lorenz, A. Thess, K.M. Duchardt, et al., J. Gene. Med., 14 (2012), pp. 428-439.

[219] L. Liu, Y. Wang, L. Miao, Q. Liu, S. Musetti, J. Li, et al., Mol. Ther., 26 (2018), pp. 45-55. [220] T.F. Gajewski, Semin. Oncol., 42 (2015), pp. 663-671.

[221] T.F. Gajewski, L. Corrales, J. Williams, B. Horton, A. Sivan, S. Spranger, Adv. Exp. Med. Biol., 1036 (2017), pp. 19-31.

[222] N. Hilf, S. Kuttruff-Coqui, K. Frenzel, V. Bukur, S. Stevanović, C. Gouttefangeas, et al., Nature, 565 (2019), pp. 240-245.

[223] D.B. Keskin, A.J. Anandappa, J. Sun, I. Tirosh, N.D. Mathewson, S. Li, et al., Nature, 565 (2019), pp. 234-239. 
[224] P.A. Ott, Z. Hu, D.B. Keskin, S.A. Shukla, J. Sun, D.J. Bozym, et al., Nature, 547 (2017), pp. 217-221. 